\title{
Statins in Acute Ischemic Stroke: A Systematic Review
}

\author{
Keun-Sik Hong, ${ }^{a}$ Ji Sung Lee ${ }^{\mathrm{b}}$ \\ a'Department of Neurology, Inje University Ilsan Paik Hospital, Goyang, Korea \\ ${ }^{\mathrm{b}}$ Clinical Research Center, Asan Medical Center, Seoul, Korea
}

Background and Purpose Statins have pleiotropic effects of potential neuroprotection. However, because of lack of large randomized clinical trials, current guidelines do not provide specific recommendations on statin initiation in acute ischemic stroke (AIS). The current study aims to systematically review the statin effect in AIS.

Methods From literature review, we identified articles exploring prestroke and immediate post-stroke statin effect on imaging surrogate markers, initial stroke severity, functional outcome, and short-term mortality in human AIS. We summarized descriptive overview. In addition, for subjects with available data from publications, we conducted meta-analysis to provide pooled estimates.

Results In total, we identified 70 relevant articles including 6 meta-analyses. Surrogate imaging marker studies suggested that statin might enhance collaterals and reperfusion. Our updated meta-analysis indicated that prestroke statin use was associated with milder initial stroke severity (odds ratio [OR] [95\% confidence interval], 1.24 [1.05-1.48]; $P=0.013$ ), good functional outcome $(1.50[1.29-1.75] ; P<0.001)$, and lower mortality $(0.42[0.21-0.82]$ $P=0.0108)$. In-hospital statin use was associated with good functional outcome (1.31 [1.121.53]; $P=0.001)$, and lower mortality $(0.41$ [0.29-0.58]; $P<0.001)$. In contrast, statin withdrawal was associated with poor functional outcome (1.83 [1.01-3.30]; $P=0.045)$. In patients treated with thrombolysis, statin was associated with good functional outcome (1.44 [1.10-1.89]; $P=0.001)$, despite an increased risk of symptomatic hemorrhagic transformation (1.63 [1.04-2.56]; $P=0.035)$.

Conclusions The current study findings support the use of statin in AIS. However, the findings were mostly driven by observational studies at risk of bias, and thereby large randomized clinical trials would provide confirmatory evidence.

Keywords Statins; Acute ischemic stroke; Stroke severity; Outcome; Mortality; Symptomatic hemorrhagic transformation

\author{
Correspondence: Keun-Sik Hong \\ Department of Neurology, Stroke Center, \\ Ilsan Paik Hospital, Inje University, \\ 170 Juhwa-ro, Ilsanseo-gu, Goyang \\ 10380, Korea \\ Tel: +82-31-910-7680 \\ Fax: +82-31-910-7368 \\ E-mail:nrhks@paik.ac.kr \\ Received: March 17, 2015 \\ Revised: April 2, 2015 \\ Accepted: April 4, 2015 \\ The authors have no financial conflicts of \\ interest.
}

\section{Introduction}

Randomized controlled trials (RCTs) have demonstrated that statins are effective for primary and secondary stroke prevention, and the benefit of statins might be largely driven by lipid-lowering effect. Beyond lipid-lowering effect, experimental studies have shown that statins have pleiotropic effects of anti-inflammatory action, antioxidant effect, antithrombotic action and facilitation of clot lysis, endothelial nitric oxide synthetase upregulation, plaque stabilization, low-density lipoprotein (LDL) oxidation reduction, and angiogenesis. ${ }^{1-8}$ These pleiotropic effects potentially benefit in acute ischemia of the brain and heart. In 
addition, animal experiments have shown angiogenesis, neurogenesis, and synaptogenesis in acute cerebral ischemia. ${ }^{9}$ Thereby, statins are potentially neurorestorative as well as neuroprotective in acute cerebral ischemia.

In patients with acute coronary syndrome acute coronary syndrome or undergoing percutaneous coronary intervention, large observational studies, RCTs, and meta-analyses showed that statins improved the outcome. ${ }^{10-17}$ Reflecting these evidences, the current cardiology guidelines recommend that 1) for patients with acute coronary syndrome, high-intensity statin therapy should be initiated or continued in all patients with ST elevation myocardial infarction and no contraindications (Class I; Level of Evidence B) ${ }^{18}$ 2) statins, in the absence of contraindications, regardless of baseline LDL-C and diet modification, should be given to post-unstable angina/non-ST elevation myocardial infarction patients, including postrevascularization patients. (Class I; Level of Evidence A), ${ }^{19}$ and 3) for patients undergoing percutaneous coronary intervention, administration of a high-dose statin is reasonable before percutaneous coronary intervention to reduce the risk of periprocedural MI (Class IIa; Level of Evidence A for statin naïve patients and LOE B for those on chronic statin therapy). ${ }^{20}$

Despite the anticipated benefit of statins in acute ischemic stroke (AIS), no large randomized trial has been conducted as in acute coronary syndrome. The current systematic review aims to systematically review the statin effect in AIS.

\section{Methods}

Using search terms of acute stroke and statin, 2,510 abstracts published until 31 December 2014 (including Epub ahead of print) were identified from PubMed search and reviewed by one author (Hong KS.). Then, we selected articles of human beings and AIS written in English. Manual review of references in articles identified 4 additional articles. As a results, the current systematic review included 70 articles: 30 articles of prestroke statin effect, 11 of in-hospital statin effect, 4 of statin withdrawal effect, 17 of statin effect in patients treated with thrombolysis, 8 of RCTs, 4 of prestroke statin effect on poststroke infection, and 7 studies with imaging surrogate markers (11 articles overlapped) (Figure 1).

For a descriptive overview, we tabulated articles according to each subject. If plausible, we conducted meta-analysis to estimate a pooled effect of statin effect in AIS. For this meta-analysis, only the original publications (excluding meta-analysis articles), which provided relevant odds ratio (OR) or hazard ratio (HR) with 95\% confidence interval (CI), were included. We did not contact authors of studies to request incomplete or unpublished data. To generate a pooled-estimate using a random-effect model, we used multivariable adjusted ORs or HRs and 95\% CIs. However, if adjusted ORs were not provided, unadjusted ORs were used in limited cases ( 1 study for prestroke statin effect on functional outcome, 2 studies for prestroke statin effect on mortality, 2 studies for prestroke statin effect on initial stroke severity, 1 study for

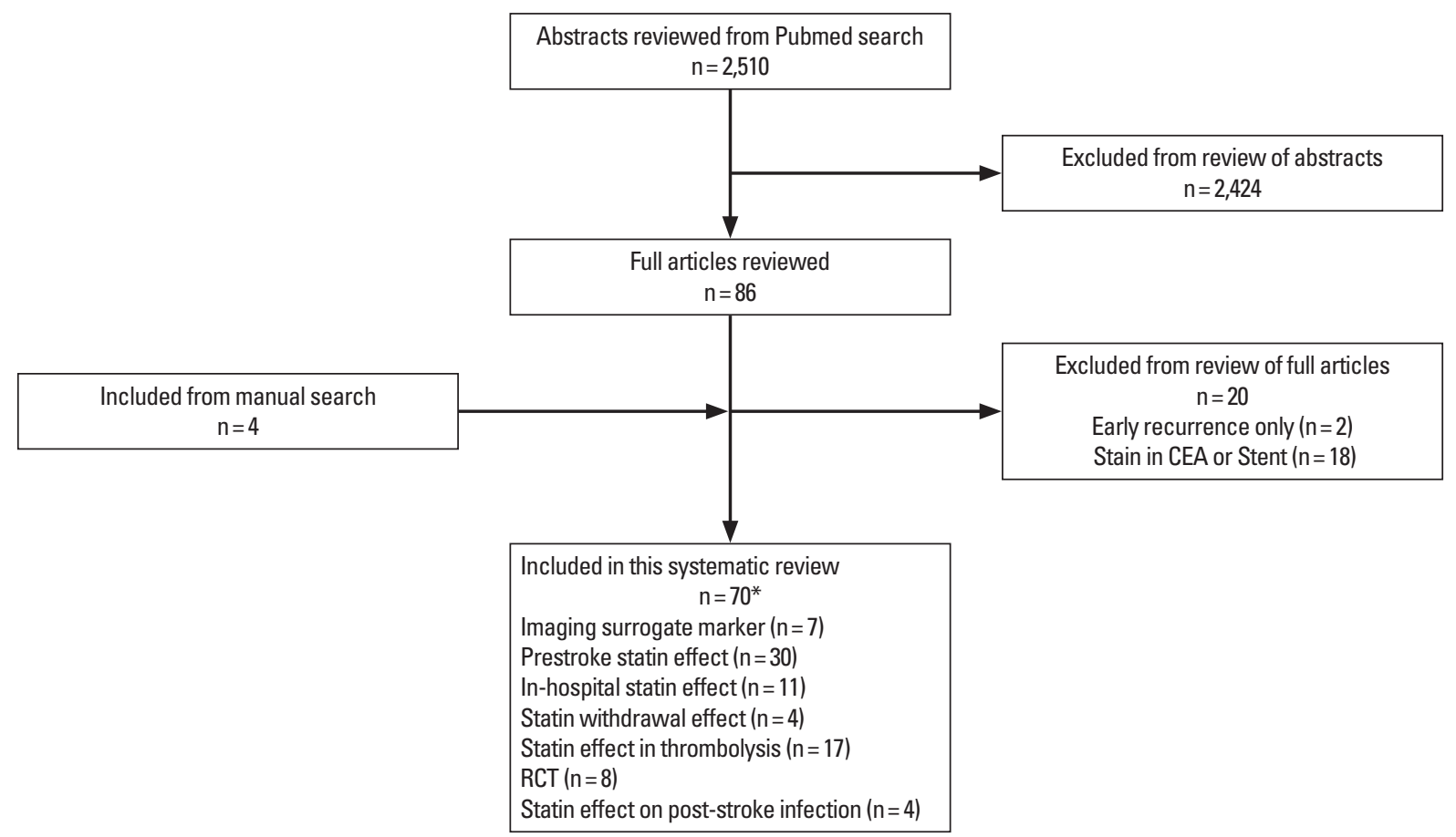

Figure 1. Summary of study selection. *11 articles were overlapped. CEA, carotid endarterectomy; RCT, randomized controlled trial. 
prestroke statin effect on mortality in patients with thrombolysis, and 1 study for statin effect on post-stroke infection).

We explored for sources of inconsistency $\left(\mathrm{I}^{2}\right)$ and heterogeneity. Heterogeneity was assessed by the $P$ value of $\chi^{2}$ statistics and by the $I^{2}$ statistics. Heterogeneity was considered significant if the $P$ value of $\chi^{2}$ statistics was $<0.10$. For $\mathrm{I}^{2}$ statistics, we regarded $\mathrm{I}^{2}$ of $<40 \%$ as minimal, $40 \%-75 \%$ as modest, and $>75 \%$ as substantial. ${ }^{21}$ Publication bias was assessed graphically with a funnel plot and statistically with the Begg's test when 5 or more studies were available.

\section{Results}

\section{Imaging surrogate marker studies}

We identified 7 studies of prestroke statin effect on imaging surrogate markers in AIS: collaterals on conventional or CT angiography in 4, infarction volume on diffusion-weighted image (DWI) in 2, and reperfusion on perfusion MRI in 1 study (Table 1). ${ }^{22-28}$ Among the 4 studies assessing collaterals in patients with acute large artery occlusion within 8 to 12 hours, ${ }^{23,26-28} 1$ CT-based study showed that prestroke statin was associated with less collaterals. ${ }^{27}$ However, on the contrary, 3 conventional angiography-based studies showed that prestroke statin use was associated with more collaterals. ${ }^{23,26,28}$ Statin might enhance collaterals by inducing endothelial nitric oxide synthase activity and angiogenesis as shown in human coronary arteries. ${ }^{1,2,4,29}$

Prestroke statin effect on infarction volume was inconsistent across the 2 studies. In 1 study undergoing DWI evaluation within 48 hour (median time, 24 hours) of onset in patients with non-lacunar middle cerebral artery territory infarct, the prestroke statin group versus the no statin group had a significantly smaller infarct volume (median volume, $25.4 \mathrm{~cm}^{3}$ vs. $15.5 \mathrm{~cm}^{3}, P=0.033$ after adjusting covariates). ${ }^{22}$ In another study, prestroke statin was not associated with infarction volume. ${ }^{24}$ However, the latter study had major limitations in that about $45 \%$ of patients had lacunar infarction and less than $40 \%$ performed DWI within 24 hours. $^{24}$

In 1 small study $(\mathrm{n}=31)$ which performed serial perfusion MRIs within 4.5 hours and at 6 hours after stroke onset, prestroke statin use was associated with 2- to 3-fold greater early reperfusion in all patients as well as subgroup of intravenous tissue plasminogen activator (IV-TPA) treated patients $(74 \%) .{ }^{25}$ Statin effect of enhancing collaterals, antithrombotic effect, and facilitating fibrinolysis might lead to better early reperfusion in acute cerebral ischemia. ${ }^{1,3,5}$

\section{Prestroke statin effect in acute ischemic stroke}

We identified 30 articles ( 28 original articles, 3 meta-analyses, and 1 article providing both original data and meta-analysis

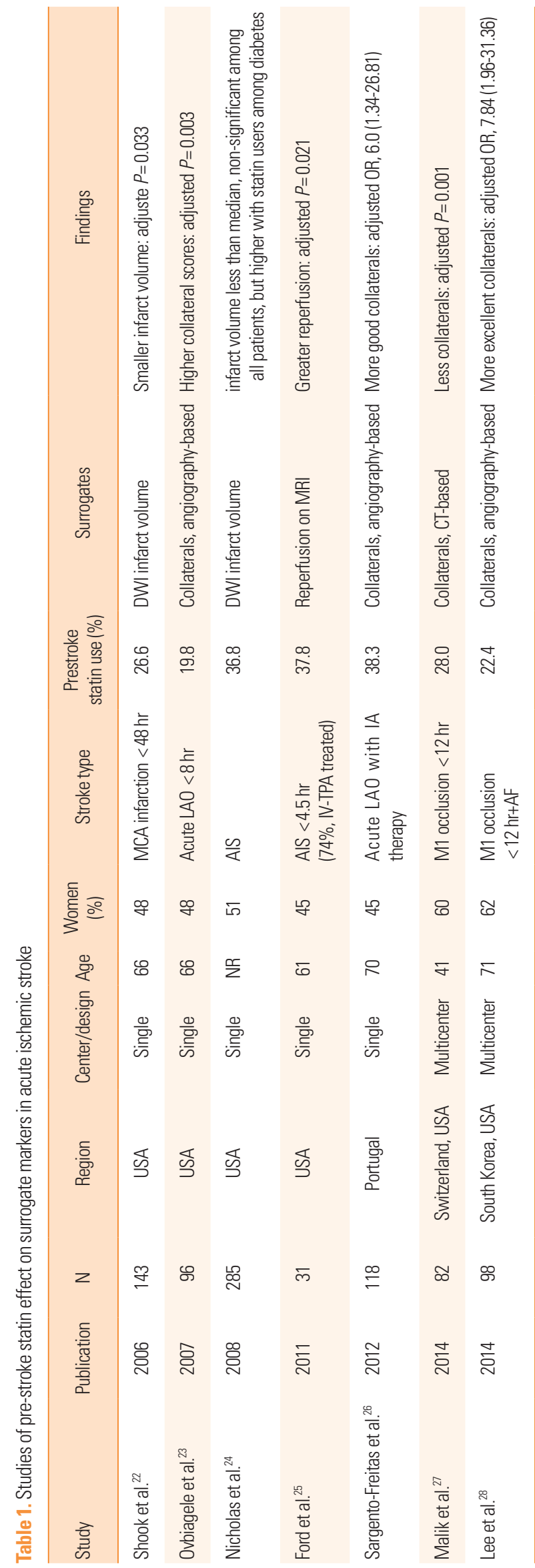




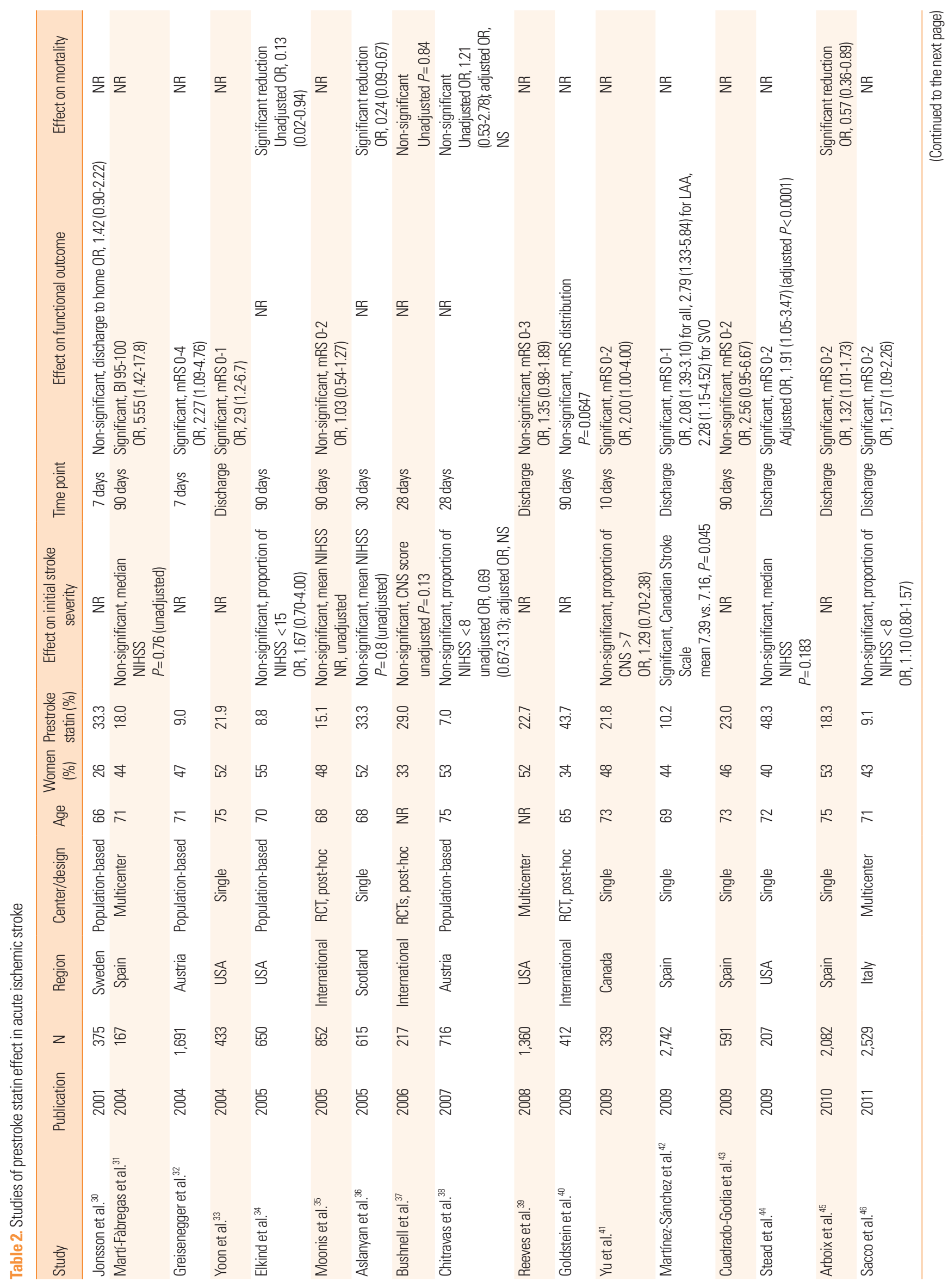




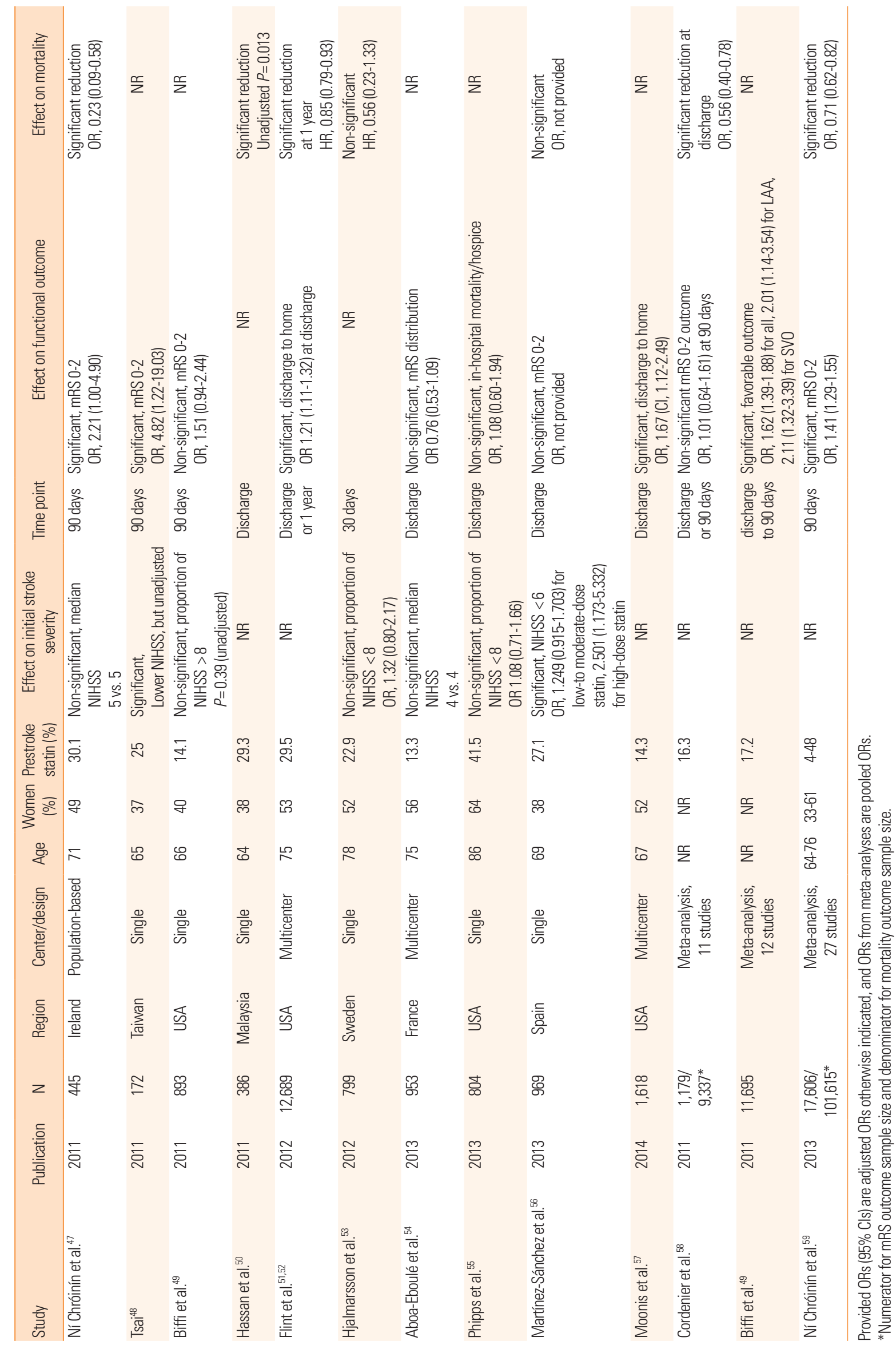


findings) evaluating prestroke statin effect on initial stroke severity, functional outcome or short-term mortality (Table 2)..$^{30-59}$

\section{Prestroke statin effect on initial stroke severity}

Seventeen original articles were identified and summarized in Table 2. Most studies used the NIHSS score to measure initial stroke severity except for 3 studies, but the employed analytic methods were highly variable across studies, comparing median NIHSS scores or proportion of mild stroke with variable thresholds. In 3 of the 17 studies, prestroke statin was significantly associated with milder initial stroke severity or higher proportion of mild stroke. ${ }^{42,48,56}$ Seven studies provided ORs with 95\% CI (adjusted ORs in 5 studies and unadjusted ORs in 2 studies). . $^{44,38,41,46,53,55,56}$ Pooling 7 studies involving 6,806 patients showed that prestroke statin use was associated with milder stroke severity at stroke onset (OR, 1.24; 95\% CI, 1.05-1.48; $P=0.013$ ). Heterogeneity across studies was not found $\left(P=0.63, \mathrm{I}^{2}=0 \%\right)$ (Figure $\left.2 \mathrm{~A}\right)$. There was no significant publication bias $(P=0.322)$ (Supplemental Figure 1). Pooling 5 studies providing adjusted ORs also showed a significant prestroke statin effect on initial stroke severity (OR, 1.24; 95\% CI, 1.04-1.48; $P=0.018$ ) (Supplemental Figure 2).

\section{Prestroke statin effect on functional outcome}

Three meta-analyses (outcome at 90 days outcome in 2 studies and discharge or 90 days in 1 study) $)^{49,58,59}$ and 21 original articles (outcome at discharge or 7-10 days in 14 studies and at 90 days in 7 studies) ${ }^{30-33,35,39-49,51,54,5,57}$ were identified and summarized in Table 2. For functional outcome endpoint, modified Rankin Scale (mRS) 0-2 was most widely employed as a good outcome (12 studies: 10 original articles and 2 meta-analyses). In 14 (12 original article and 2 meta-analyses) of the 24 studies, patients with prestroke statin were more likely to achieve good functional outcome. Pooling 19 original publications (involving 30,942 patien ts), ${ }^{30-33,35,39,41-49,51,54,55,57}$ which provided adjusted ORs (95\% CI), showed that prestroke statin use was associated with good functional outcome (OR, 1.50; 95\% CI, 1.29-1.75; $P<0.001$ ). There was a significant and modest heterogeneity across the studies $\left(P=0.002, \mathrm{I}^{2}=55 \%\right)$. However, the heterogeneity was related to the magnitude of effect rather than the direction of effect (Figure $2 B)$. A significant publication bias was found $(P=0.001)$, but it was mainly attributed to studies with relatively small sample sizes (Supplemental Figure 3). Regarding ischemic stroke subtypes, 1 meta-analysis showed that the association of prestroke statin use and good functional outcome was significant in patients with large artery atherosclerosis and small vessel occlusion, but not in cardioembolic stroke. ${ }^{49}$

\section{Prestroke statin effect on short-term mortality}

Two meta-analyses (90-day mortality) $)^{58,59}$ and 10 original articles (mortality at discharge in 3 studies, 20-30 days in 4 studies, 90 days in 2 studies, and 365 days in 1 study $)^{34,36-38,45,47,50,52,53,56}$ were identified and summarized in Table 2. In 8 (6 original articles and 2 meta-analyses) of the 12 studies, patients with prestroke statin had a lower mortality. Pooling 5 original publications (involving 4,508 patients), which provided ORs with 95\% CI (adjusted ORs in 3 studies ${ }^{36,45,47}$ and unadjusted ORs in 2 studies $\left.{ }^{34,38}\right)$, showed that prestroke statin use was associated with lower mortality (OR, 0.42; 95\% CI, 0.21-0.82; $P=0.011$ ). A significant and modest heterogeneity across the studies was found $\left(P=0.03, I^{2}=64 \%\right)$, but the treatment effect was in the same direction except for 1 study (Figure 2C). There was no significant publication bias $(P=0.624)$ (Supplemental Figure 4). Pooling 3 studies providing adjusted ORs also showed a significant association of prestroke statin use with reduced mortality (OR, 0.36; 95\% CI, 0.18-0.70; $P=0.003$ ) (Supplemental Figure 5). Two studies (involving 13,488 patients) reported adjusted HRs instead of ORs. ${ }^{52,53}$ Pooling these 2 studies also showed that prestroke statin use was associated with lower mortality (HR, 0.85; 95\% CI, 0.77-0.93; $P=0.0003)$. There was no significant heterogeneity across the studies $\left(P=0.36, \mathrm{I}^{2}=0 \%\right)$ (Figure $\left.2 \mathrm{D}\right)$.

\section{In-hospital statin effect in acute ischemic stroke}

We identified 11 articles (10 original articles and 1 meta-analysis) that assessed the in-hospital statin effect on functional outcome or short-term mortality (Table 3). . $3,47,51-53,57,59-63$

\section{In-hospital statin effect on functional outcome}

One meta-analysis (at discharge or 30 days) ${ }^{59}$ and 9 original articles (at discharge in 4 studies and at 90 days in 5 studies) $35,47,51,53,57,60-63$ assessed the in-hospital statin effect on functional outcome (Table 3). For functional outcome endpoint, mRS 0-2 outcome was most commonly used as a good functional outcome (in 7 studies: 6 original articles and 1 meta-analysis). In 7 ( 6 original article and 1 meta-analysis) of the 10 studies, patients with in-hospital statin had a better functional outcome. Pooling 8 studies (involving 37,153 patients),,$^{35,47,51,53,57,61-63}$ which provided adjusted ORs (95\% CI), showed that in-hospital statin use was associated with good functional outcome (OR, 1.31; 95\% CI, 1.12-1.53; $P=0.001)$. There was a significant and modest heterogeneity across the studies $\left(P=0.005, \mathrm{I}^{2}=65 \%\right)$, but the treatment effect was generally in the same direction except for 1 study (Figure 3A). There was no significant publication bias $(P=0.322)$ (Supplemental Figure 6). 
A Prestroke statin effect on initial stroke severity

Odds Ratio

Martínez-Sánchez Low to Mod
Studv or Subaroup

Elkind

Chitravas

Yu

Sacco

Hjalmarsson

Phipps

Martínez-Sánchez High

log[Odds Ratio]

$\begin{array}{lll}0.5128 & 0.4456 & 3.9 \%\end{array}$

$\begin{array}{lll}-0.3711 & 0.7715 & 1.3 \%\end{array}$

$\begin{array}{lll}0.2546 & 0.3125 & 7.9 \%\end{array}$

$0.0953 \quad 0.1815 \quad 23.4 \%$

$\begin{array}{lll}0.2776 & 0.2555 & 11.8 \%\end{array}$

$\begin{array}{lll}0.077 & 0.2193 & 16.0 \%\end{array}$

$0.22230 .1588 \quad 30.6 \%$

$0.9167 \quad 0.3863 \quad 5.2 \%$

Total $(95 \% \mathrm{Cl})$

$100.0 \%$

Heterogeneity: Tau $^{2}=0.00 ; \mathrm{Chi}^{2}=5.23, \mathrm{df}=7(\mathrm{P}=0.63) ; \mathrm{I}^{2}=0 \%$

Test for overall effect: $Z=2.48(P=0.01)$

Random. $95 \% \mathrm{Cl}$ Year

$1.67[0.70,4.00] 2005$

$0.69[0.15,3.13] 2007$

$1.29[0.70,2.38] 2009$

$1.10[0.77,1.57] 2011$

$1.32[0.80,2.18] 2012$

$1.08[0.70,1.66] 2013$

$1.25[0.91,1.70] 2013$

$2.50[1.17,5.33] 2013$

$1.24[1.05,1.48]$

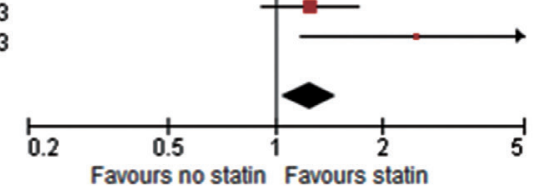

B Prestroke statin effect on good functional outcome

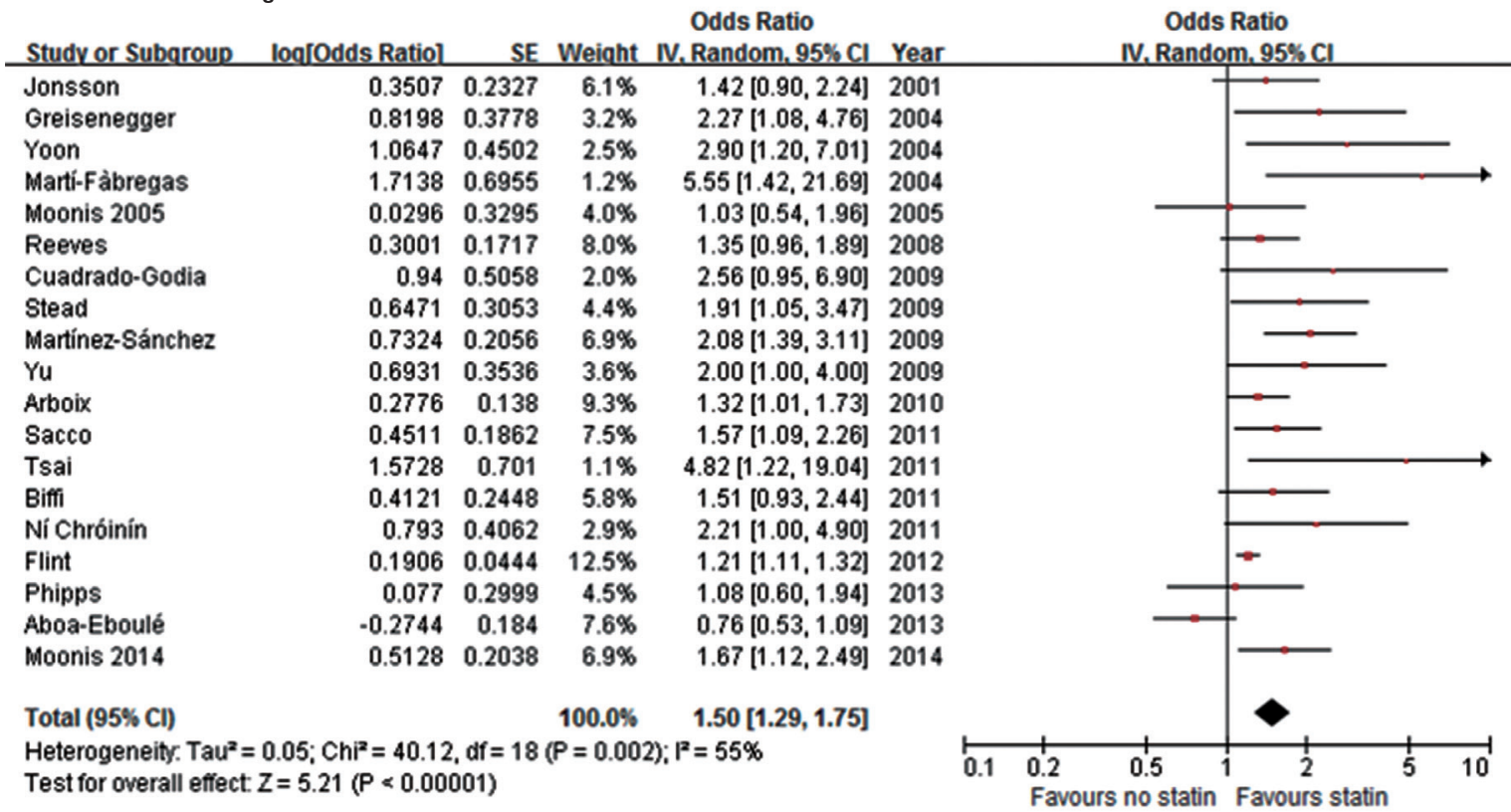

C Prestroke statin effect on short-term mortality (OR)

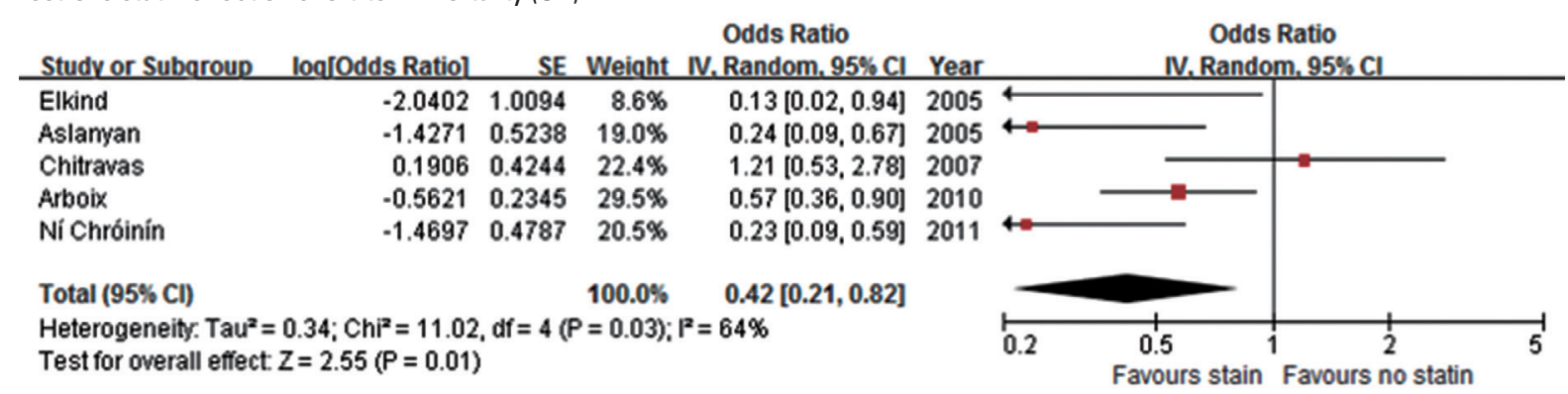

(D) Prestroke statin effect on short-term mortality (HR)

\begin{tabular}{|c|c|c|c|c|c|c|c|c|}
\hline Stuck or Subqroup & logl[Hazard Ratiol & SE & Weight & $\begin{array}{c}\text { Hazard Ratio } \\
\text { N. Random. } 95 \% \mathrm{Cl}\end{array}$ & Year & $\begin{array}{r}\text { Hazard } \\
\text { M. Randor }\end{array}$ & $\begin{array}{l}\text { Ratio } \\
\mathrm{m}, 95 \% \mathrm{Cl}\end{array}$ & \\
\hline Flint & -0.1625 & 0.0459 & $99.0 \%$ & $0.85[0.78,0.93]$ & 2012 & & & \\
\hline Hjalmarsson & -0.5798 & 0.454 & $1.0 \%$ & $0.56[0.23,1.36]$ & 2012 & & & \\
\hline Total $(95 \% \mathrm{Cl})$ & & & $100.0 \%$ & $0.85[0.77,0.93]$ & & & & \\
\hline $\begin{array}{l}\text { Heterogeneity: Tau } \\
\text { Test for overall effec }\end{array}$ & $\begin{array}{l}0.00 ; C^{2}=0.84, d f \\
Z=3.65(P=0.0003\end{array}$ & $\begin{array}{l}f=1(P= \\
3)\end{array}$ & $0.36) ; 1^{2}=$ & $=0 \%$ & & $\stackrel{1}{0.2}_{\text {Favours stain }}^{0}{ }^{1}$ & $\begin{array}{c}2 \\
\text { vours }\end{array}$ & $\begin{array}{r}5 \\
\text { atin }\end{array}$ \\
\hline
\end{tabular}

Figure 2. Association of prestroke statin use and initial stroke severity (A), good functional outcome (B), and short-term mortality (C, pooling studies providing OR; $D$, pooling studies providing HR). Values of OR or HR greater than 1.0 indicate that prestroke statin use was associated with milder initial stroke severity (A), good functional outcome (B), and higher risk of mortality (C and D). SE, standard error; IV, inverse variance; $\mathrm{Cl}$, confidence interval. 


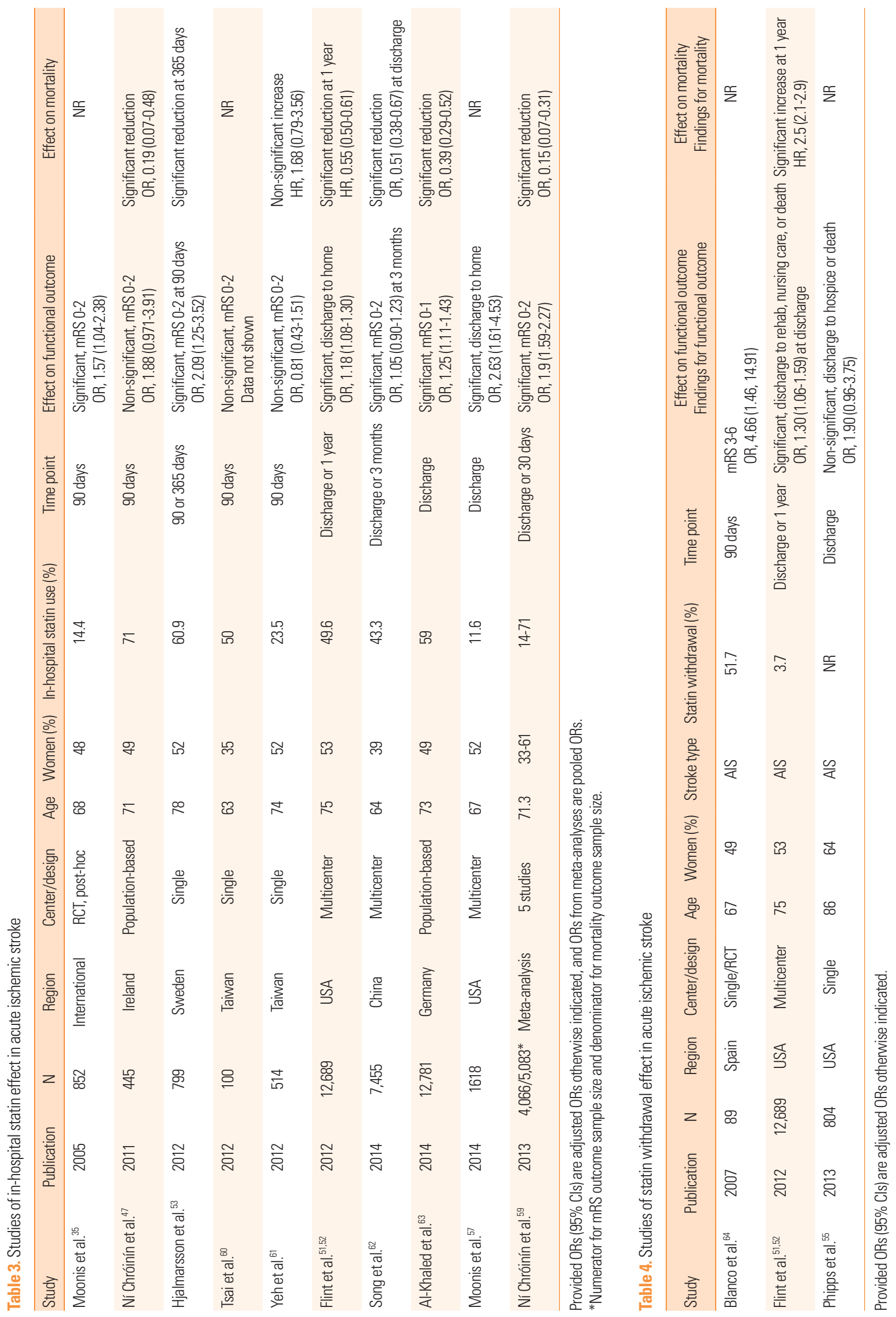


A In-hospital statin effect on good functional outcome

\begin{tabular}{|c|c|c|c|c|c|}
\hline Study or Subaroup & log[Odds Ratio] & SE & Weight & IV. Random, $95 \% \mathrm{Cl}$ & Year \\
\hline Moonis 2005 & 0.4511 & 0.2123 & $9.3 \%$ & $1.57[1.04,2.38]$ & 2005 \\
\hline Ní Chróinín & 0.6313 & 0.3736 & $3.9 \%$ & $1.88[0.90,3.91]$ & 2011 \\
\hline Flint & 0.1655 & 0.0494 & $24.7 \%$ & $1.18[1.07,1.30]$ & 2012 \\
\hline Yeh & -0.2107 & 0.3231 & $5.0 \%$ & $0.81[0.43,1.53]$ & 2012 \\
\hline Hjalmarsson & 0.7372 & 0.266 & $6.8 \%$ & $2.09[1.24,3.52]$ & 2012 \\
\hline Moonis 2014 & 0.967 & 0.2774 & $6.3 \%$ & $2.63[1.53,4.53]$ & 2014 \\
\hline Al-Khaled & 0.2231 & 0.0686 & $22.7 \%$ & $1.25[1.09,1.43]$ & 2014 \\
\hline Song & 0.0488 & 0.0807 & $21.3 \%$ & $1.05[0.90,1.23]$ & 2014 \\
\hline Total $(95 \% \mathrm{Cl})$ & & & $100.0 \%$ & $1.31[1.12,1.53]$ & \\
\hline
\end{tabular}

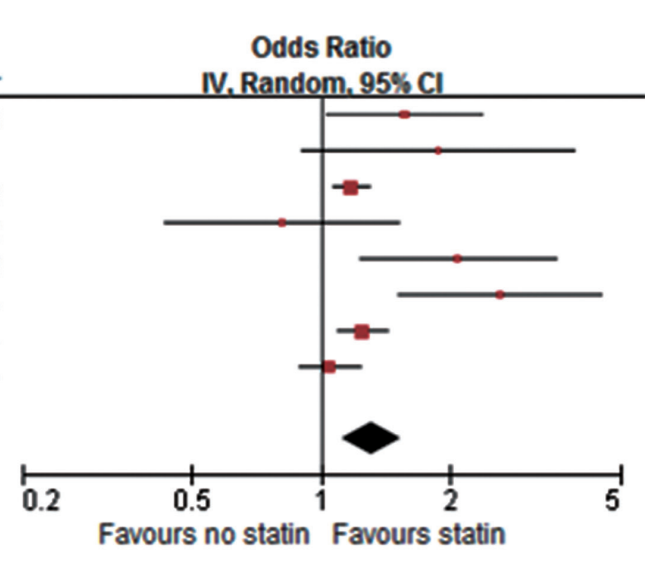

B In-hospital statin effect on short-term mortality (OR)

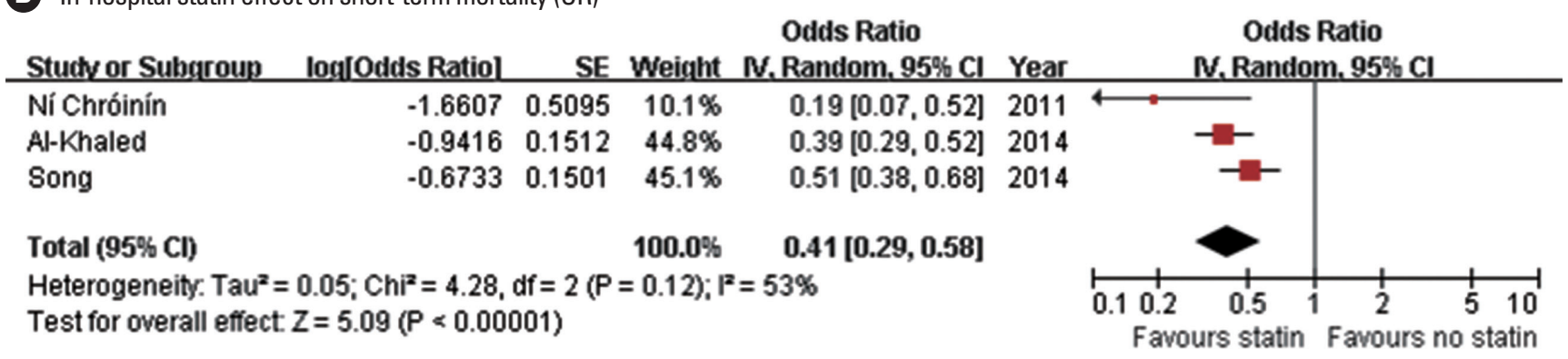

C In-hospital statin effect on short-term mortality (HR)

\begin{tabular}{|c|c|c|c|c|c|c|c|}
\hline Stucte or Subgroup & log[Hazard Ratio] & SE & Weight & $\begin{array}{c}\text { Hazard Ratio } \\
\text { N. Random, } 95 \% \text { Cl }\end{array}$ & Year & $\begin{array}{c}\text { Hazard Ratio } \\
\text { N. Random. } 95 \% \text { Cl }\end{array}$ & \\
\hline Yeh & 0.5188 & 0.385 & $26.0 \%$ & $1.68[0.79,3.57]$ & 2012 & & \\
\hline Hjalmarsson & -1.1087 & 0.2555 & $32.9 \%$ & $0.33[0.20,0.54]$ & 2012 & & \\
\hline Flint & -0.5978 & 0.0528 & $41.1 \%$ & $0.55[0.50,0.61]$ & 2012 & & \\
\hline Total $(95 \% \mathrm{Cl})$ & & & $100.0 \%$ & $0.62[0.33,1.16]$ & & & \\
\hline \multicolumn{8}{|c|}{ 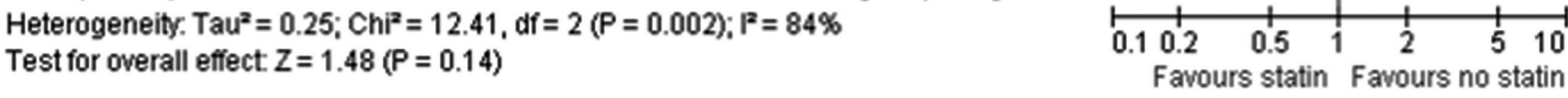 } \\
\hline
\end{tabular}

Figure 3. Association of in-hospital statin use and good functional outcome (A), and short-term mortality (B, pooling studies providing ORs; C, pooling studies providing HRs). Values of OR or HR greater than 1.0 indicate that in-hospital statin use was associated with good functional outcome (A), and higher risk of mortality (B and C). SE, standard error; IV, inverse variance; $\mathrm{Cl}$, confidence interval.

\section{In-hospital statin effect on short-term mortality}

One meta-analysis (at discharge or 30 days) and 6 original articles (at discharge in 2 studies, 90 days in 2 studies, and 365 days in 2 studies) assessed the in-hospital statin effect on shortterm mortality (Table 3 ). Of the 7 studies, 6 studies ( 5 original article and 1 meta-analysis) showed that patients with in-hospital statin use had a significantly lower mortality, whereas 1 study reported non-significant increase in mortality with in-hospital statin use. Three original articles provided adjusted ORs with 95\% CI, and pooling these 3 studies involving 20,681 patients showed that in-hospital statin use was associated with lower mortality (OR, 0.41; 95\% CI, 0.29-0.58; P<0.001). A non-significant and modest heterogeneity across the studies was found across the studies $\left(P=0.12, \mathrm{I}^{2}=53 \%\right)$ (Figure 3B). Three original articles provided adjusted HRs with $95 \% \mathrm{CI}$, and pooling these 3 studies involving 14,002 patients showed that in-hospital statin use was not significantly associated with lower mortality (HR, 0.62; 95\% CI, 0.33-1.16; $P=0.138)$. A significant and substantial heterogeneity across the studies was found $(P=$ $0.002, \mathrm{I}^{2}=84 \%$ ) (Figure 3C).

Statin withdrawal effect in acute ischemic stroke

Statin withdrawal effect was tested in one RCT performed in a single center, ${ }^{64}$ and explored in three observational studies (Table 4). ${ }^{51,52,55}$ Of 3 studies assessing functional outcome (adjusted ORs for 90-day mRS 3-6 outcome in one study and for 
Statin withdrawal effect on poor functional outcome

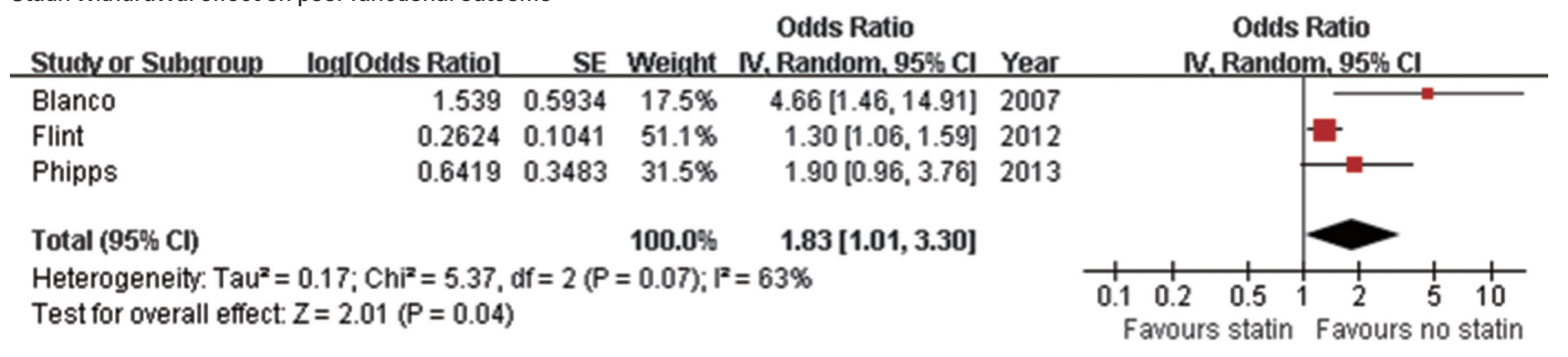

Figure 4. Association of statin withdrawal during hospitalization and poor functional outcome. Values of ORs greater than 1.0 indicate that statin withdrawal during hospitalization was associated with poor functional outcome. SE, standard error; IV, inverse variance; Cl, confidence interval.

poor discharge disposition in 2 studies), ${ }^{51,55,64} 2$ studies showed that statin withdrawal was associated with poor outcome. ${ }^{51,64}$ Pooling the 3 studies involving 13,583 patients showed that statin withdrawal was associated with poor functional outcome (OR, 1.83; 95\% CI, 1.01-3.30; $P=0.045$ ). A significant and modest heterogeneity across the studies was found $(P=0.07$, $\mathrm{I}^{2}=63 \%$ ) (Figure 4). In one study, statin withdrawal was associated with an increased risk of 1-year mortality (HR, 2.5; 95\% CI, 2.1-2.9; $P<0.001)$. $^{52}$

\section{Statin effect in patients with thrombolysis}

We identified 17 studies ( 15 original articles, 4 meta-analyses, and 2 article providing both original data and meta-analysis findings) exploring statin effect on functional outcome, mortality, or symptomatic hemorrhagic transformation (SHT) in patients with thrombolysis (IV-TPA only in 12 studies, intra-arterial thrombolysis [IA] only in 2 studies, and IV-TPA or IA in 3 studies) (Table 5). 58,59,65-79

\section{Statin effect on functional outcome in patients with thrombolysis}

Fifteen studies (14 original articles, 3 meta-analyses, and 2 article providing both original data and meta-analysis findings) reported the statin effect on functional outcome. ${ }^{59,65,67-74,76-79}$ Good functional outcome was defined as mRS 0-1 in 6 studies and mRS 0-2 in 8 studies, and mix-up of variable criteria in 1 metaanalysis. In earlier 3 meta-analyses, ${ }^{59,73,75}$ statin was not associated with good functional outcome, whereas 5 studies among the 14 original articles showed that statin was associated with good functional outcome. ${ }^{65,67,72,76,78}$ Pooling 11 original articles (involving 10,876 patients, 1 article providing 2 ORs for both statin before and after and statin after only), ${ }^{65,67,69-74,76,78,79}$ which provided adjusted ORs with $95 \% \mathrm{CI}$, showed that statin use in patients treated with thrombolysis was associated with good functional outcome (OR, 1.44; 95\% CI, 1.10-1.89; $P=0.008)$. A significant and modest heterogeneity was found across the studies $(P<0.001$,
$\mathrm{I}^{2}=67 \%$ ), but the direction of treatment effect was generally consistent except for 2 studies (Figure 5A). There was no significant publication bias $(P=0.493)$ (Supplemental Figure 7).

Statin effect on mortality in patients with thrombolysis

Statin effect on the 90-mortality in patients with thrombolysis was assessed in 2 meta-analyses and 6 original articles (Table 5)..$^{58,59,68,71,73,74,76,79}$ Among the 3 meta-analyses, 1 meta-analysis showed that statin use was associated with increased mortality. ${ }^{59}$ Of the 6 original articles, 1 study showed that, statin use was significantly associated with lower mortality, ${ }^{76}$ but the other studies found no significant effect. Pooling 5 original articles (involving 8,237 patients), ${ }^{71,73,74,76,79}$ which provided ORs with 95\% CI (adjusted OR in 4 studies and unadjusted OR in 1 study), showed that statin use in patients treated with thrombolysis neither increased nor decreased mortality (OR, 0.87; 95\% CI, 0.58-1.32; $P=0.518$ ). A significant and modest heterogeneity across the studies was found $\left(P=0.02, \mathrm{I}^{2}=65 \%\right)$ (Figure $\left.5 \mathrm{~B}\right)$. There was no significant publication bias $(P=0.142)$ (Supplemental Figure 8 ). Pooling 4 studies providing adjusted ORs also showed that statin use was not associated with mortality in patients with thrombolysis (OR, 0.77; 95\% CI, 0.48-1.25; P= 0.289) (Supplemental Figure 9).

\section{Statin effect on symptomatic hemorrhagic transformation in patients with thrombolysis}

Sixteen studies (15 original articles, 3 meta-analyses, and 2 article providing both original data and meta-analysis findings) reported the statin effect on SHT (Table 5). ${ }^{58,65-79}$ In $2^{58,75}$ of the 3 meta-analyses and $3^{68,72,78}$ of the 15 original articles, statin use was associated with an increased risk of SHT. Pooling 9 original articles (involving 10,419 patients), ${ }^{67,68,70-74,76,78}$ which provided adjusted ORs with 95\% CI, showed that statin use in patients treated with thrombolysis was associated with an increased risk of SHT (OR, 1.63; 95\% CI, 1.04-2.56; $P=0.035$ ). A significant and modest heterogeneity across the studies was found $(P=$ 


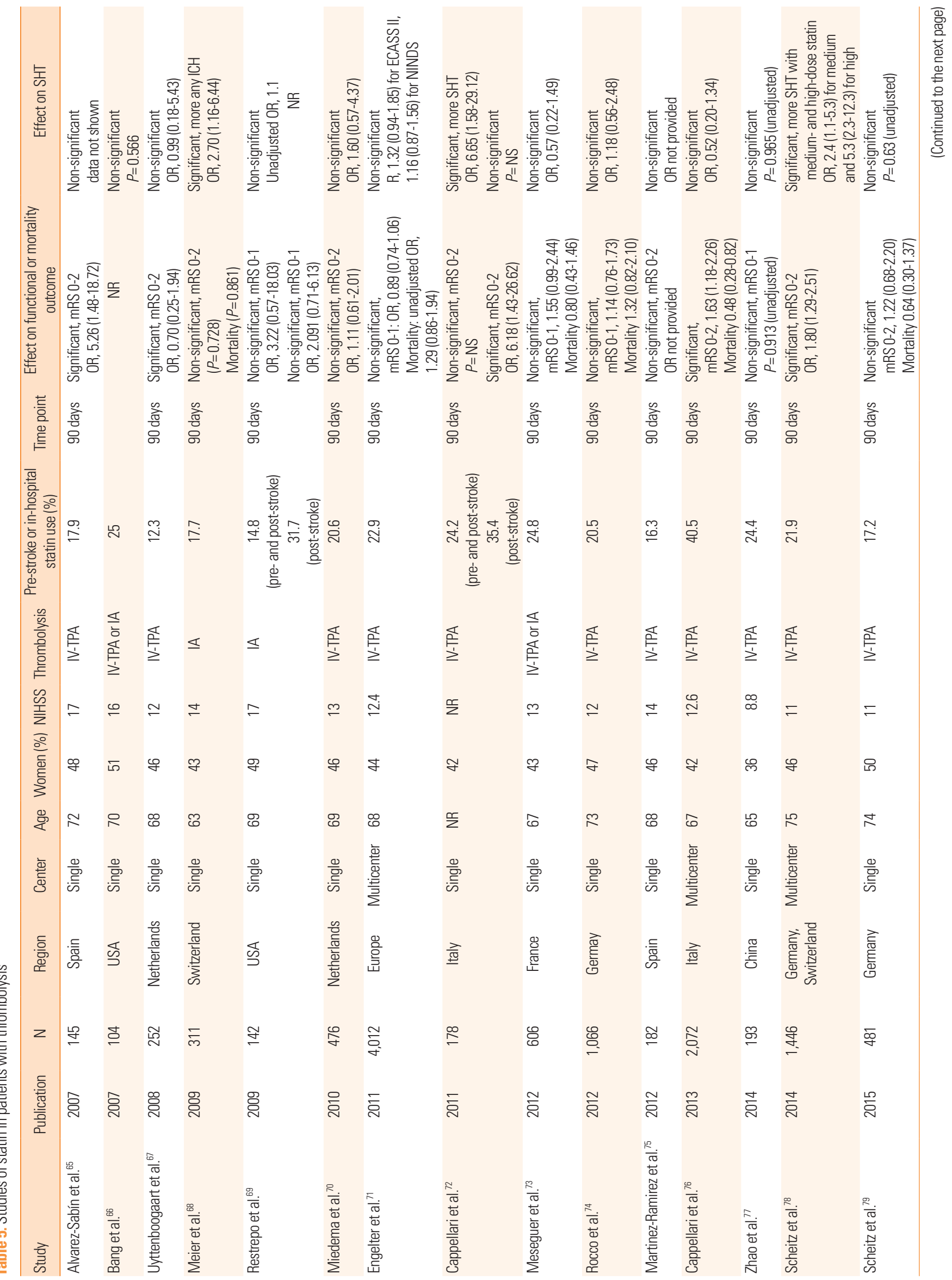




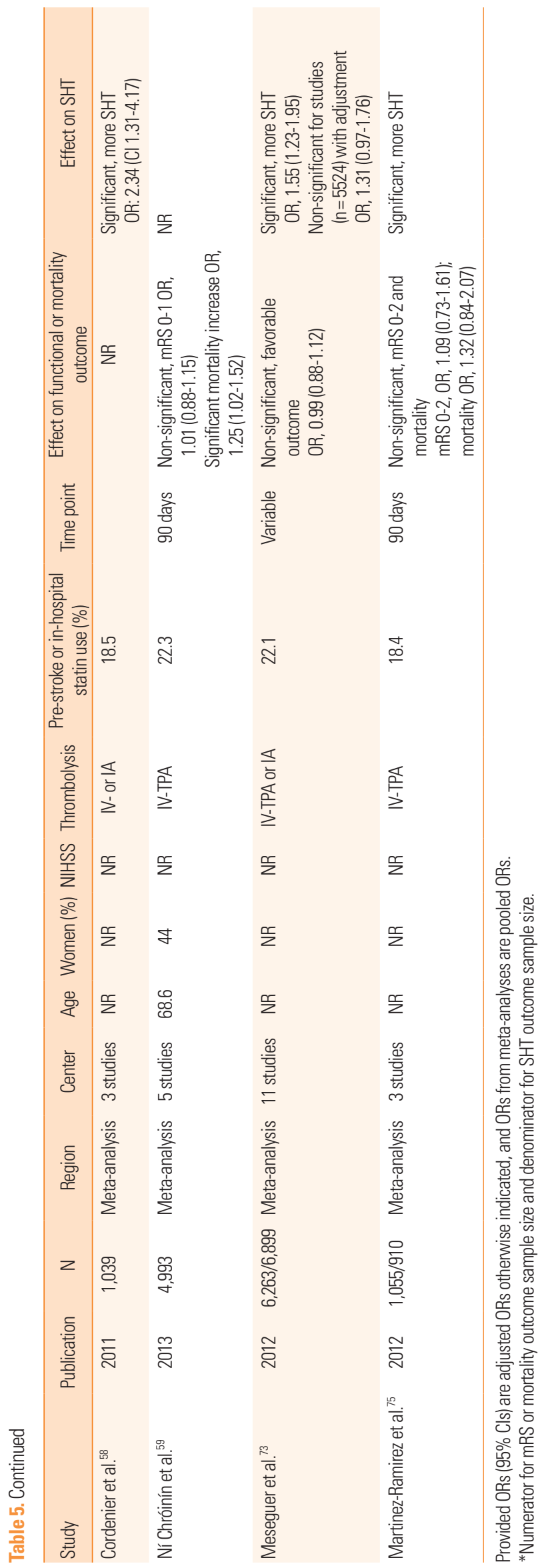

$0.003, \mathrm{I}^{2}=65 \%$ ) (Figure 5C). There was no significant publication bias $(P=0.655)$ (Supplemental Figure 10).

\section{Statin effect on post-stroke infection}

Since statins have immunomodulatory effect, several studies assessed the association of statin use with post-stroke infection. Among 4 studies, ${ }^{79-82} 1$ study $^{79}$ showed that post-stroke pneumonia was less frequent in patients with prestroke statin use among IV-TPA treated patients (Table 6). Pooling 3 original articles (involving 2,638 patients), ${ }^{79,80,82}$ which provided ORs with 95\% CI (adjusted OR in 2 studies and unadjusted OR in 1 study), showed that the effect of statin on post-stroke infection was not significant (OR, 0.91; 95\% CI, 0.30-2.77; $P=0.867$ ). There was a significant and modest heterogeneity across the studies $\left(P=0.03, I^{2}=70 \%\right)$ (Figure 6). Pooling 2 studies providing adjusted ORs also showed that statin use was not associated with post-stroke infection (OR, 1.16; 95\% CI, 0.07-18.87; $P=0.916)$ (Supplemental Figure 11).

\section{Randomized controlled trials}

The Stroke Prevention by Aggressive Reduction in Cholesterol Levels (SPARCL) study randomized patients at 1 to 6 months after stroke. Therefore, the trial results cannot be considered as a reliable guide for statin use in AIS. Literature search identified 6 RCTs (statin withdrawal effect on functional outcome in 1, statin effect on functional outcome in 1 , recurrent stroke within 90 days in 1 , early neurological improvement in 1 , and surrogate markers in 2 studies), ${ }^{64,83-87}$ and one meta-analysis (Table 7) ${ }^{88}$ In addition, one phase $1 \mathrm{~B}$ dose-finding single arm trial using an adaptive design of increasing lovastatin up to 10 $\mathrm{mg} / \mathrm{kg} /$ day assessed the safety of high-dose statin, which showed that the final model-based estimate of toxicity was $13 \%$ (95\% CI 3\%-28\%) for a dose of $8 \mathrm{mg} / \mathrm{kg} /$ day. ${ }^{89}$ There has been no large RCT, and the sample sizes of the published RCTs were small (ranging between 33 and 392), not adequately powered to assess the statin effect in AIS.

Markers of Inflammation after Simvastatin in Ischemic Cortical Stroke (MISTICS) was a pilot, double-blind, randomized, multicenter clinical trial, comparing inflammatory biomarkers between simvastatin versus placebo in patients with cortical AIS. $^{84}$ The trial failed to demonstrate the anti-inflammatory effect of statin in human stroke despite rapid and sustained reduction of total and LDL-C levels with simvastatin. For clinical endpoints, patients on simvastatin compared to those on placebo were more likely to achieve NIHSS improvement 4 or more at 3 days, but did not achieve better 90 -day mRS outcome.

Fast Assessment of Stroke and Transient Ischemic Attack to Prevent Early Recurrence (FASTER) was a relatively large 
A Statin effect on good functional outcome in thrombolysis

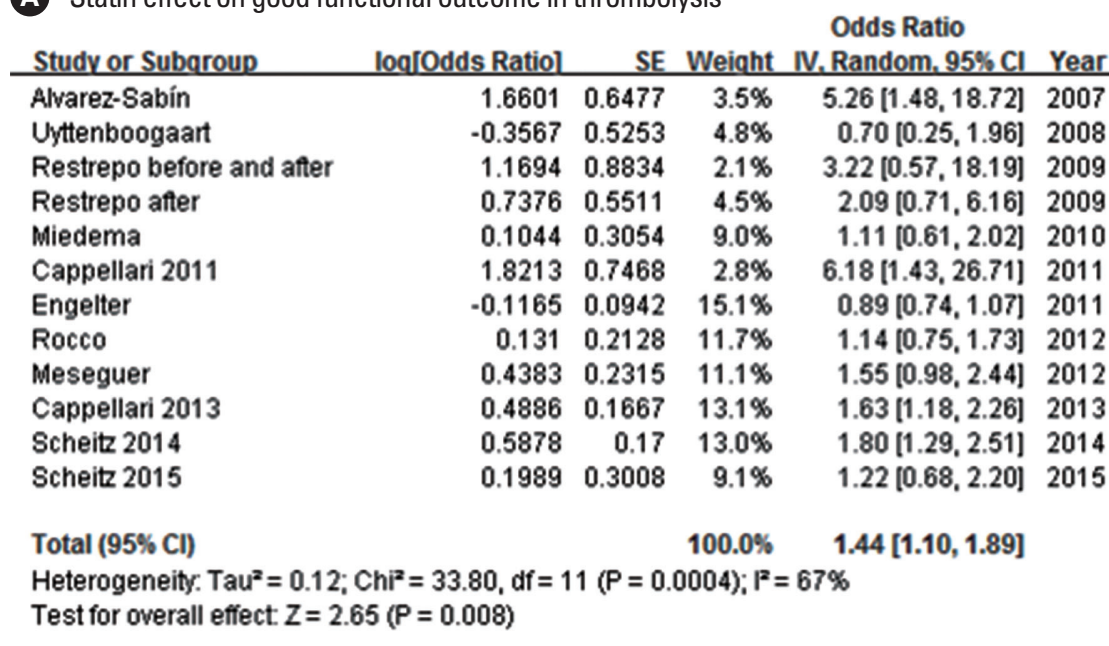

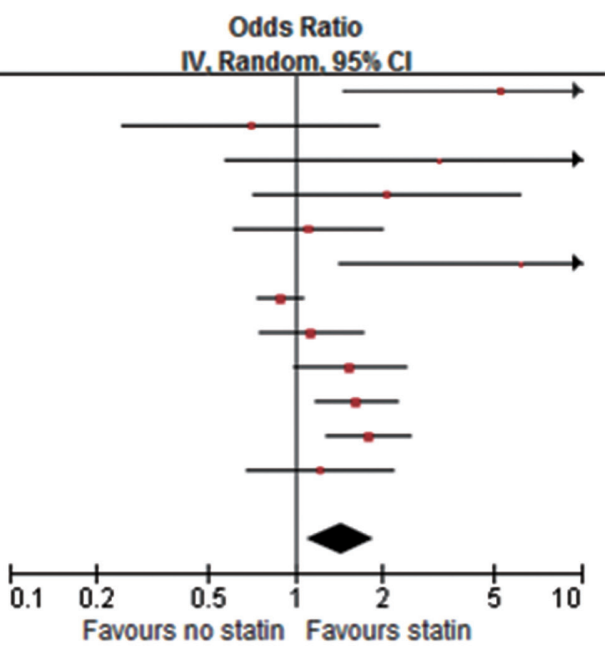

B Statin effect on 90-day mortality in patients with thrombolysis

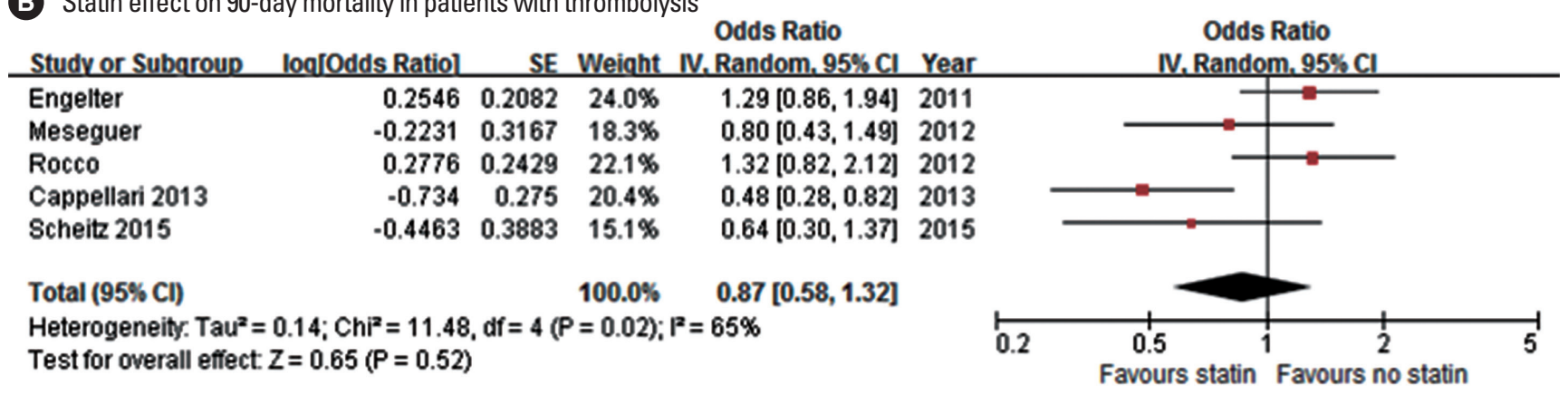

C Statin effect on symptomatic hemorrhagic transformation in patients with thrombolysis

\begin{tabular}{|c|c|c|c|c|}
\hline Study or Subqroup & log[Odds Ratio] & SE & Weight & $\begin{array}{l}\text { Odds Ratio } \\
\text { IV, Random, } 95 \% \mathrm{Cl}\end{array}$ \\
\hline Uyttenboogaart & -0.0101 & 0.8698 & $5.0 \%$ & $0.99[0.18,5.44]$ \\
\hline Meier & 0.9933 & 0.4435 & $10.6 \%$ & $2.70[1.13,6.44]$ \\
\hline Miedema & 0.47 & 0.5266 & $9.1 \%$ & $1.60[0.57,4.49]$ \\
\hline Cappellari 2011 & 1.8946 & 0.7535 & $6.1 \%$ & $6.65[1.52,29.12]$ \\
\hline Engelter & 0.2776 & 0.1732 & $15.8 \%$ & $1.32[0.94,1.85]$ \\
\hline Meseguer & -0.5621 & 0.4903 & $9.7 \%$ & $0.57[0.22,1.49]$ \\
\hline Rocco & 0.1655 & 0.3803 & $11.8 \%$ & $1.18[0.56,2.49]$ \\
\hline Cappellari 2013 & -0.6539 & 0.4875 & $9.8 \%$ & $0.52[0.20,1.35]$ \\
\hline Scheitz Med & 0.8755 & 0.4042 & $11.3 \%$ & $2.40[1.09,5.30]$ \\
\hline Scheitz High & 1.6677 & 0.4295 & $10.8 \%$ & $5.30[2.28,12.30]$ \\
\hline Total $(95 \% \mathrm{Cl})$ & & & $100.0 \%$ & $1.63[1.04,2.56]$ \\
\hline \multicolumn{5}{|c|}{$\begin{array}{l}\text { Heterogeneity. } \text { Tau }^{2}=0.31 ; \mathrm{Chi}^{2}=25.45, \mathrm{df}=9(P=0.003) ;\left.\right|^{2}=65 \% \\
\text { Test for overall effect: } Z=2.11(P=0.03)\end{array}$} \\
\hline
\end{tabular}

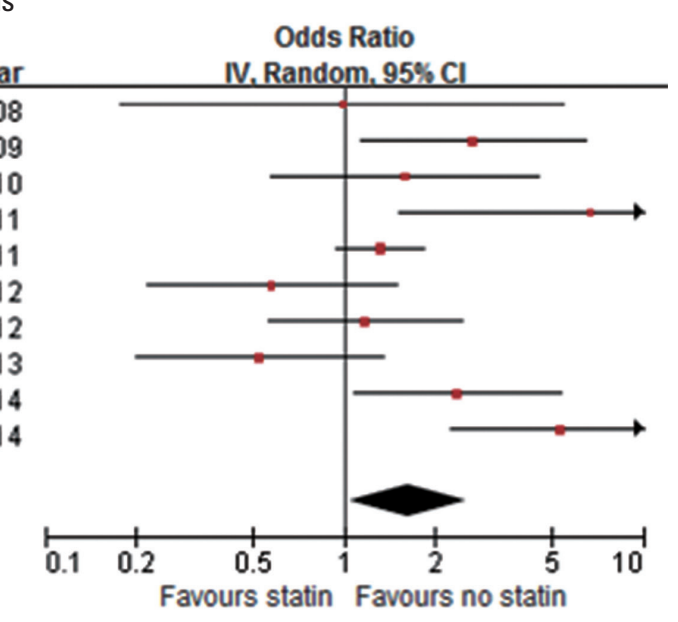

Figure 5. Association of statin use and good functional outcome (A), 90-day mortality (B), and symptomatic hemorrhagic transformation (C). Values of ORs than 1.0 indicate that statin use was associated with good functional outcome (A), higher risk of mortality (B), and higher risk of symptomatic hemorrhagic transformation (C). $\mathrm{SE}$, standard error; IV, inverse variance; $\mathrm{Cl}$, confidence interval.

RCT comparing simvastatin 40 mg versus placebo in 392 patients with a transient ischemic attack or minor stroke within the previous 24 hours. ${ }^{83}$ Because of the slow enrollment rate, the trial was early terminated after enrolling only 392 patients and thereby substantially underpowered. The rate of the primary endpoint of recurrent stroke within 90 days was $10.6 \%$ for the simvastatin group versus $7.3 \%$ for the placebo group (relative risk $[\mathrm{RR}], 1.3$; 95\% $\mathrm{CI}, 0.7-2.4 ; P=0.64)$.

Although the benefit of early statin initiation in AIS has not been demonstrated in RCTs, the harmful effect of statin withdrawal was demonstrated in a small, single center, randomized trial. ${ }^{64}$ In the trial, 89 patients with prestroke statins and hemi- 
Table 6. Studies of statin effect on post-stroke infection

\begin{tabular}{|c|c|c|c|c|c|c|c|c|c|}
\hline Study & Publication & N & Region & Center/design & Age & $\begin{array}{c}\text { Women } \\
(\%)\end{array}$ & Population & $\begin{array}{c}\text { Prestroke statin use } \\
(\%)\end{array}$ & $\begin{array}{l}\text { Effect on infection } \\
\text { Findings }\end{array}$ \\
\hline Rodríguez de Antonio et al. ${ }^{80}$ & 2011 & 2,045 & Spain & Single & 69 & 43 & AIS & 15.0 & $\begin{array}{l}\text { Non-significant } \\
\text { unadjusted OR, } 0.89 \text { (0.61-1.29) }\end{array}$ \\
\hline Rodríguez-Sanz et al. ${ }^{81}$ & 2013 & 1,385 & Spain & Single & 68 & 40 & AIS & 26.5 & $\begin{array}{l}\text { Non-significant } \\
\text { OR not provided }\end{array}$ \\
\hline Becker et al. ${ }^{82}$ & 2013 & 112 & USA & Single & 57 & 35 & AIS & 70.5 & $\begin{array}{l}\text { Non-significant } \\
\text { OR, } 5.37 \text { (0.81-35.37) }\end{array}$ \\
\hline Scheitz et al. ${ }^{79}$ & 2015 & 481 & Germany & Single & 74 & 50 & AIS with IV-TPA & 17.3 & $\begin{array}{l}\text { Significant, less pneumonia } \\
\text { OR, } 0.31(0.10-0.94)\end{array}$ \\
\hline
\end{tabular}

Statin effect on post-stroke infection risk

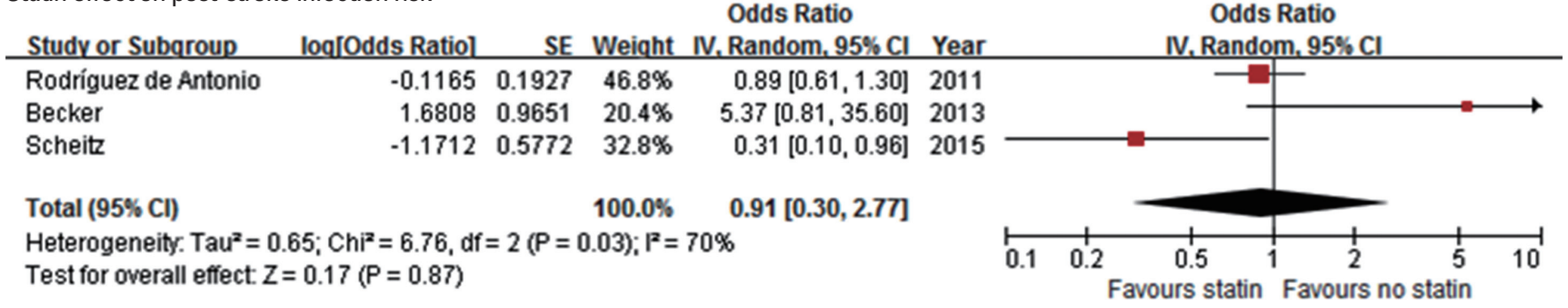

Figure 6. Association of statin use and post-stroke infection risk. Values of ORs greater than 1.0 indicate that statin use was associated with an increased risk of post-stroke infection. SE, standard error; IV, inverse variance; Cl, confidence interval.

spheric ischemic stroke within 24 hours were randomized to either transient statin withdrawal for the first 3 days or to continuation of statin treatment with atorvastatin $20 \mathrm{mg}$ daily. The withdrawal group versus the continuation group was more likely to have poor functional outcome at 90 days (mRS 3-6, primary endpoint) (60.0\% vs. $39.0 \%$; adjusted OR [ $95 \% \mathrm{CI}$ ], 4.66 [1.46 to 14.91]), to experience early neurological deterioration of worsening NIHSS score 4 or more (65.2\% vs. $20.9 \%$; adjusted OR [ $95 \%$ $\mathrm{CI}$ ], 8.67 [3.05 to 24.63]), and to have a greater infarct volume increase between 4 and 7 days. Based on this trial results, the American Stroke Association guidelines recommend the continuation of statin therapy during the acute period among patients already taking statins at the time of ischemic stroke (Class IIa; LOE B). However, the American Stroke Association guidelines do not provide specific recommendations regarding when to start statins in AIS patients with no prior statin treatment. ${ }^{90}$

In a recent meta-analysis including 7 published and unpublished RCTs involving 431 patients with AIS or transient ischemic attack within 2 weeks, all-cause mortality did not differ between the statin and placebo groups (OR 1.51, 95\% CI 0.60 to 3.81$){ }^{88}$

\section{Discussion}

Our systematic review could not find the evidence of statin benefit in AIS from RCTs although a small RCT demonstrated the harm of statin withdrawal. The results from observational studies were inconsistent. However, our updated meta-analysis using available data from original publications suggests that 1 ) prestroke statin use might reduce stroke severity at stroke onset, functional disability, and short-term mortality, 2) immediate post-stroke statin treatment might reduce functional disability and short-term mortality, whereas statin withdrawal might lead to worse outcome, and 3) in patients treated with thrombolysis, statins might improve functional outcome despite of an increased risk of SHT.

Imaging surrogate maker studies would provide a proof-ofconcept for potential mechanisms of statin benefit in AIS. In general, surrogate marker studies suggest that statin benefit might be mediated by more collaterals and better reperfusion in AIS, and the findings in human with AIS are consonant with animal experiment study findings of improved cerebral flow secondary to upregulation of endothelial nitric oxide synthase, enhanced fibrinolysis, and reducing infarct size with statin treatment. ${ }^{3-5}$

Investigating the prestroke statin effect would be a useful approach to assess the neuroprotective effect of statins in AIS. However, an RCT testing prestroke statin effect is not practically feasible because it requires a tremendous sample size. Given the neuroprotective effect of statins from animal experiment studies and imaging surrogate marker studies in human stroke, prestroke statin might limit ischemic brain damage and lead to mild stroke severity, and this effect, in part, might contribute to 


\begin{tabular}{|c|c|c|c|c|c|c|c|c|}
\hline 픙 & $\stackrel{\dddot{q}}{z}$ & $\frac{q}{z}$ & $\stackrel{\frac{⿱}{z}}{z}$ & $\frac{⿱ 亠 ⿰ 口}{z}$ & 容怘 & $\frac{⿱ x}{2}$ & $\stackrel{\frac{⿱}{z}}{z}$ & $\stackrel{\Upsilon}{z}$ \\
\hline 㟧 & 哭 & 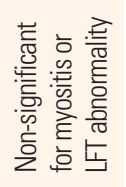 & 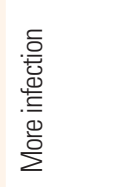 & 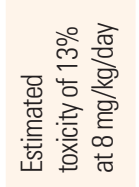 & 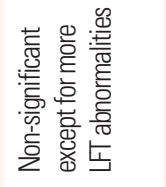 & $\stackrel{\frac{⿱ 亠 ⿻}{z}}{2}$ & $\stackrel{\text { 品 }}{2}$ & 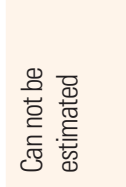 \\
\hline 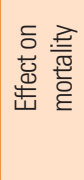 & $\stackrel{\frac{c}{2}}{2}$ & $\frac{m}{z}$ & 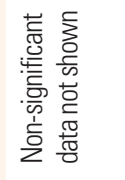 & $\stackrel{\frac{m}{z}}{2}$ & 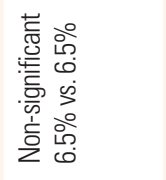 & $\frac{\mathfrak{c}}{2}$ & 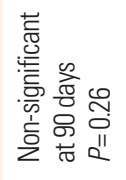 & 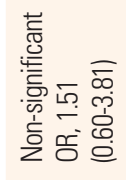 \\
\hline 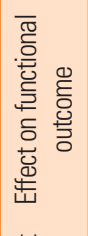 & 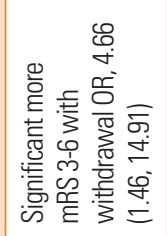 & $\frac{⿱ 亠 ⿰ 口 口}{z}$ & 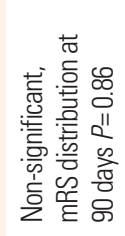 & $\frac{\dddot{m}}{z}$ & 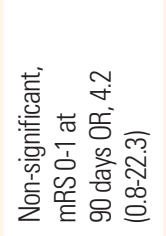 & $\frac{\text { qu }}{z}$ & 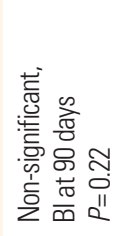 & 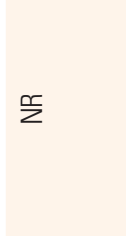 \\
\hline 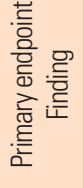 & 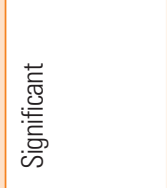 & 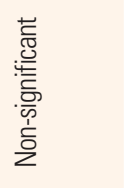 & 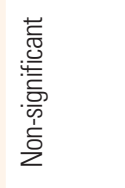 & 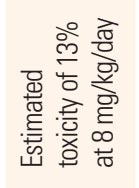 & 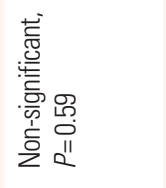 & 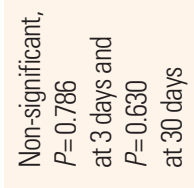 & & \\
\hline 르을 & 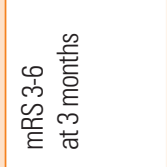 & 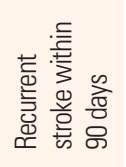 & 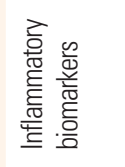 & 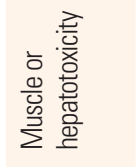 & 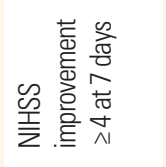 & 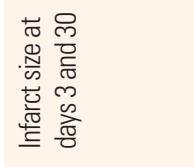 & 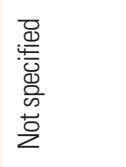 & \\
\hline $\begin{array}{l}\text { 预 } \\
\bar{\Sigma}\end{array}$ & $\stackrel{m}{\rightleftharpoons}$ & $\frac{\mathscr{q}}{2}$ & $\simeq$ & เ & $\stackrel{\llcorner}{\stackrel{\sim}{\sim}}$ & $r$ & $\stackrel{\llcorner}{\llcorner}$ & $\frac{\mathfrak{m}}{z}$ \\
\hline 产 & g g & $F$ & 足 & กิ & œ & $\mathscr{N}$ & $F$ & $\stackrel{\Upsilon}{z}$ \\
\hline 娄 & $\hat{0}$ & 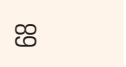 & œ & $\widetilde{0}$ & $\stackrel{2}{\wedge}$ & 8 & 8 & $\frac{\Upsilon}{z}$ \\
\hline 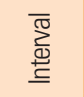 & 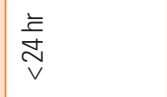 & $\stackrel{\grave{i}}{\stackrel{i}{V}}$ & 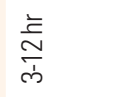 & $\underset{v}{\stackrel{E}{V}}$ & $\underset{\text { V̀ }}{\stackrel{亡}{V}}$ & 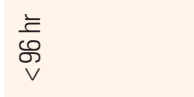 & $\frac{\mathfrak{c}}{z}$ & $v \frac{\mathscr{m}}{\frac{\mathbb{d}}{\xi}}$ \\
\hline 咅 & 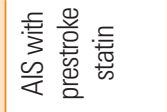 & $\stackrel{\infty}{\mathbb{Z}}$ & $\frac{\infty}{\Psi}$ & $\frac{\infty}{\leftarrow}$ & $\frac{\infty}{\tau}$ & $\frac{\infty}{\pi}$ & 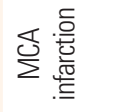 & $\stackrel{\infty}{\Psi}$ \\
\hline 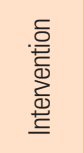 & 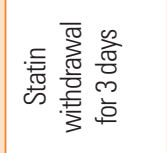 & 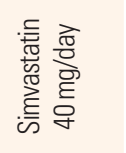 & 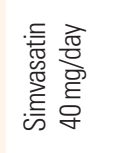 & 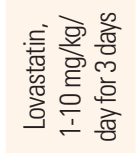 & 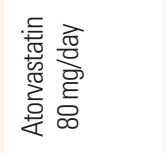 & 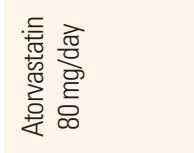 & 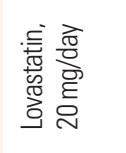 & 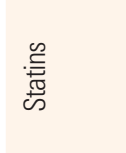 \\
\hline 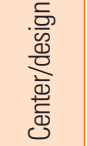 & $\begin{array}{l}\frac{0}{\bar{T}} \\
\frac{\tilde{E}}{\omega}\end{array}$ & 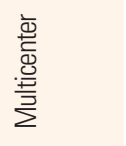 & 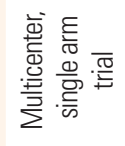 & 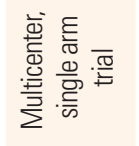 & $\begin{array}{l}\frac{0}{\bar{T}} \\
\dot{c}\end{array}$ & 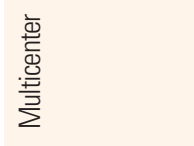 & 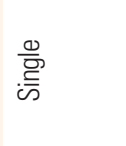 & 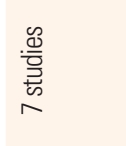 \\
\hline 흥 & $\begin{array}{l}\text { 离 } \\
\text { con }\end{array}$ & 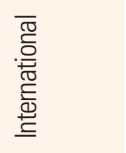 & $\begin{array}{l}\text { 高 } \\
\text { con }\end{array}$ & 氙 & 촐 & 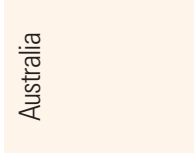 & 든 & 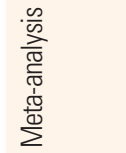 \\
\hline$z$ & ® & జ్ల & 8 & ஜ & $\widetilde{\sigma}$ & g & 吕 & $\overline{\mathscr{\gamma}}$ \\
\hline 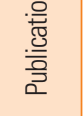 & 总 & 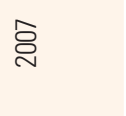 & 总 & : & $\overline{\bar{\nu}}$ & స్ & ఫ్ & $\overline{\bar{\sigma}}$ \\
\hline te & 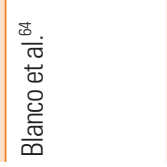 & 哭 & 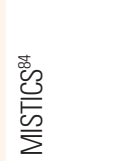 & 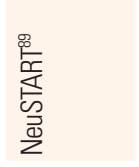 & 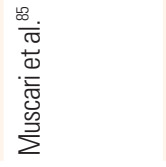 & 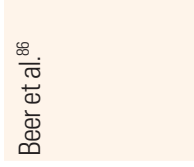 & 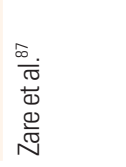 & 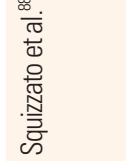 \\
\hline
\end{tabular}


the better functional outcome with prestroke statin use. However, most published articles failed to show that prestroke statin was associated with less severe stroke. Since the statin benefit would not be substantial, the small sample sizes of the most published articles might account for the negative results. Previously, no meta-analysis has explored this statin effect. In our meta-analysis including data from 6,806 patients, pre-stroke statin use was associated with a 1.24-fold greater odds of stroke with milder severity, suggesting statin's neuroprotective effect during acute cerebral ischemia in human. A recent Korean large retrospective study $(n=8,340)$ using propensity score matching analysis showed that prestroke stroke use was associated with mild stroke severity at presentation. ${ }^{91}$

An earlier post-hoc analysis of the Stroke Prevention by Aggressive Reduction in Cholesterol Levels study explored statin effect on functional outcome in patients with recurrent stroke (i.e., prestroke statin effect on recurrent stroke), which had an advantage of randomizing patients either to statin or placebo. The authors suggested that the outcome of recurrent ischemic cerebrovascular events might be improved among statin users as compared with patients on placebo. However, the result was significant for the overall cohort, including patients with eventfree as well as those with recurrent stroke. The analysis restricted patients with recurrent ischemic stroke outcome did not show a significant benefit of statin on functional outcome. ${ }^{40}$

For the statin effect on functional outcome, 2 previous metaanalyses (patients included in functional outcome analysis: $\mathrm{n}=11,965$ in one study by Biffi et al. ${ }^{49}$ and $\mathrm{n}=17,152$ in another by Ní Chróinín et al. ${ }^{59}$ ) showed the association of prestroke statin use with good functional outcome. In accord with previous results, the finding of our updated meta-analysis including more patients $(n=30,942)$ strongly suggests that prestroke statin use might improve functional outcome. It is unclear whether, in addition to neuroprotection during ischemia, statin's facilitation of recovery after stroke as shown in animal experiments, ${ }^{9}$ leads to the better functional outcome. In a recent large observational study in Korea, even after adjusting initial stroke severity as well as other covariates, prestroke statin users compared to non-users were more likely to achieve good outcome (mRS 0-2 outcome) at discharge, suggesting statin's dual effect of neuroprotection and neurorestoration. ${ }^{91}$

Our updated meta-analyses showed that statin whether administered prior to stroke or immediately after stroke was associated with better survival, as observed in earlier meta-analyses. ${ }^{58,59}$ In addition to better functional outcome, preventing recurrent vascular event might account for the statin benefit of reducing short-term mortality. In a meta-analysis of 7 RCTs in patients with acute coronary syndrome, statin initiation during acute period was associated with reduced mortality. ${ }^{92}$ Therefore, statin therapy might have beneficial effect of reducing mortality in patients with acute ischemia in the brain as well as in the heart. In patients with recent acute coronary syndrome, high intensity statin versus moderate intensity statin had a greater benefit in reducing mortality. ${ }^{93}$ For patients with AIS, a large observational study showed that 1-year survival benefit with statin during AIS was greater with high-dose statins than with low-dose statins. ${ }^{52}$ However, there has been no evidence from RCTs.

Worse outcome with statin withdrawal in a small RCT might indirectly indicate the statin benefit in AIS ${ }^{64}$ Supporting the RCT finding, a large observational study ${ }^{51}$ and our meta-analysis showed the harmful effect of statin withdrawal during AIS. In the RCT, statin withdrawal even for a brief period of 3 days led to early neurological deterioration and greater infarct volume increase as well as 90-day worse functional outcome. Therefore, the potential mechanisms might be related to, rather than LDLlowering, pleiotropic effects on endothelial function, inflammation, platelet, and fibrinolytic system. ${ }^{1,3-5}$

Statins have antithrombotic and fibrinolytic effects, and in the Stroke Prevention by Aggressive Reduction in Cholesterol Levels trial patients on high-dose atorvastatin compared to those on placebo had more hemorrhagic strokes. Therefore, among neurologists, there has been concern on the increased risk of hemorrhagic transformation with statin use in AIS, particularly for patients treated with thrombolysis. The current meta-analysis showed that statin was associated with an increased risk of SHT after thrombolysis, as shown in a previous meta-analysis. ${ }^{58} \mathrm{How}$ ever, despite the increased risk of SHT, the functional outcome was better with statin use in our meta-analysis, which was not observed in earlier meta-analyses. ${ }^{59,73,75}$ Therefore, prestroke statin use would not be a contraindication for thrombolysis. However, whether statin therapy should be initiated immediately after reperfusion therapy in AIS as in acute coronary syndrom needs to be tested with RCTs.

This study has several limitations. Our findings were almost exclusively driven from data of observational studies, which are at risk of bias. In most outcomes, we found a large amount of heterogeneity in the results among the included studies. However, in general, the heterogeneity was brought by the magnitude of effect rather than the direction of effect. For several outcomes, unadjusted ORs as well as adjusted ORs were combined to generate pooled estimates. However, unadjusted ORs used were from limited articles with relatively small sample sizes. Therefore, the effect on our findings was not substantial as shown in additional analyses pooling adjusted ORs only. The current study did not assess the statin effect on early recurrent 
stroke, which would be of interest of topics on future investigation. Finally, if the literature search fails to find out all relevant articles, the result of meta-analysis is at risk of bias. As we only searched PubMed, several relevant articles might be missed. However, to minimize this risk, we performed additional hand search by reviewing references listed in the included original publications and meta-analyses.

In conclusion, the current systematic review supports the benefit of statins in AIS. However, the findings were largely driven by observational studies, and thereby the benefit needs to be confirmed by well-designed, large RCTs.

\section{Disclosure}

Hong KS has received lecture honoraria from Pfizer Korea related to the current topic.

\section{References}

1. Endres M, Laufs U, Huang Z, Nakamura T, Huang P, Moskowitz MA, et al. Stroke protection by 3-hydroxy-3-methylglutaryl (HMG)-CoA reductase inhibitors mediated by endothelial nitric oxide synthase. Proc Natl Acad Sci US A 1998;95:8880-8885.

2. Kureishi Y, Luo Z, Shiojima I, Bialik A, Fulton D, Lefer DJ, et al. The HMG-CoA reductase inhibitor simvastatin activates the protein kinase Akt and promotes angiogenesis in normocholesterolemic animals. Nat Med 2000;6:1004-1010.

3. Laufs U, Gertz K, Huang P, Nickenig G, Böhm M, Dirnagl U, et al. Atorvastatin upregulates type III nitric oxide synthase in thrombocytes, decreases platelet activation, and protects from cerebral ischemia in normocholesterolemic mice. Stroke 2000; 31:2442-2449.

4. Amin-Hanjani S, Stagliano NE, Yamada M, Huang PL, Liao JK, Moskowitz MA. Mevastatin, an HMG-CoA reductase inhibitor, reduces stroke damage and upregulates endothelial nitric oxide synthase in mice. Stroke 2001;32:980-986.

5. Asahi M, Huang Z, Thomas S, Yoshimura S, Sumii T, Mori T, et al. Protective effects of statins involving both eNOS and tPA in focal cerebral ischemia. J Cereb Blood Flow Metab 2005;25: 722-729.

6. Goldstein LB. Statins and ischemic stroke severity: cytoprotection. Curr Atheroscler Rep 2009; 11:296-300.

7. Jain MK, Ridker PM. Anti-inflammatory effects of statins: clinical evidence and basic mechanisms. Nat Rev Drug Discov 2005; 4:977-987.

8. Moon GJ, Kim SJ, Cho YH, Ryoo S, Bang OY. Antioxidant effects of statins in patients with atherosclerotic cerebrovascular disease. J Clin Neurol 2014;10:140-147.
9. Chen J, Zhang ZG, Li Y, Wang Y, Wang L, Jiang H, et al. Statins induce angiogenesis, neurogenesis, and synaptogenesis after stroke. Ann Neurol 2003;53:743-751.

10. Stenestrand U, Wallentin L; Swedish Register of Cardiac Intensive Care (RIKS-HIA). Early statin treatment following acute myocardial infarction and 1-year survival. JAMA 2001; 285:430-436.

11. Fonarow GC, Wright RS, Spencer FA, Fredrick PD, Dong W, Every N, et al. Effect of statin use within the first 24 hours of admission for acute myocardial infarction on early morbidity and mortality. Am J Cardiol 2005;96:611-616.

12. Lenderink T, Boersma E, Gitt AK, Zeymer U, Wallentin L, Van de Werf F, et al. Patients using statin treatment within $24 \mathrm{~h}$ after admission for ST-elevation acute coronary syndromes had lower mortality than non-users: a report from the first Euro Heart Survey on acute coronary syndromes. Eur Heart J 2006; 27:1799-1804.

13. Nagashima M, Koyanagi R, Kasanuki H, Hagiwara N, Yamaguchi J, Atsuchi N, et al. Effect of early statin treatment at standard doses on long-term clinical outcomes in patients with acute myocardial infarction (the Heart Institute of Japan, Department of Cardiology Statin Evaluation Program). Am J Cardiol 2007; 99:1523-1528.

14. Schwartz GG, Olsson AG, Ezekowitz MD, Ganz P, Oliver MF, Waters D, et al. Effects of atorvastatin on early recurrent ischemic events in acute coronary syndromes: the MIRACL study: a randomized controlled trial. JAMA 2001;285:1711-1718.

15. de Lemos JA, Blazing MA, Wiviott SD, Lewis EF, Fox KA, White $\mathrm{HD}$, et al. Early intensive vs a delayed conservative simvastatin strategy in patients with acute coronary syndromes: phase $\mathrm{Z}$ of the A to Z trial. JAMA 2004;292:1307-1316.

16. Cannon CP, Braunwald E, McCabe CH, Rader DJ, Rouleau JL, Belder $\mathrm{R}$, et al. Intensive versus moderate lipid lowering with statins after acute coronary syndromes. N Engl J Med 2004;350: 1495-1504.

17. Winchester DE, Wen X, Xie L, Bavry AA. Evidence of pre-procedural statin therapy a meta-analysis of randomized trials. $J$ Am Coll Cardiol 2010;56:1099-1109.

18. O’Gara PT, Kushner FG, Ascheim DD, Casey DE Jr, Chung MK, de Lemos JA, et al. 2013 ACCF/AHA guideline for the management of ST-elevation myocardial infarction: a report of the American College of Cardiology Foundation/American Heart Association Task Force on Practice Guidelines. Circulation 2013; 127:e362-e425.

19. Anderson JL, Adams CD, Antman EM, Bridges CR, Califf RM, Casey DE Jr, et al. 2012 ACCF/AHA focused update incorporated into the ACCF/AHA 2007 guidelines for the management of patients with unstable angina/non-ST-elevation myo- 
cardial infarction: a report of the American College of Cardiology Foundation/American Heart Association Task Force on Practice Guidelines. Circulation 2013;127:e663-e828.

20. Levine GN, Bates ER, Blankenship JC, Bailey SR, Bittl JA, Cercek B, et al. 2011 ACCF/AHA/SCAI Guideline for Percutaneous Coronary Intervention: executive summary: a report of the American College of Cardiology Foundation/American Heart Association Task Force on Practice Guidelines and the Society for Cardiovascular Angiography and Interventions. Circulation 2011;124:2574-2609.

21. Higgins JPT, Green S. Cochrane Handbook for Systematic Reviews of Interventions. West Sussex, UK: Cochrane Collaboration and John Wiley \& Sons Ltd, 2008.

22. Shook SJ, Gupta R, Vora NA, Tievsky AL, Katzan I, Krieger DW. Statin use is independently associated with smaller infarct volume in nonlacunar MCA territory stroke. J Neuroimaging 2006;16:341-346.

23. Ovbiagele B, Saver JL, Starkman S, Kim D, Ali LK, Jahan R, et al. Statin enhancement of collateralization in acute stroke. $\mathrm{Neu}$ rology 2007;68:2129-2131.

24. Nicholas JS, Swearingen CJ, Thomas JC, Rumboldt Z, Tumminello P, Patel SJ. The effect of statin pretreatment on infarct volume in ischemic stroke. Neuroepidemiology 2008;31:48-56.

25. Ford AL, An H, D’Angelo G, Ponisio R, Bushard P, Vo KD, et al. Preexisting statin use is associated with greater reperfusion in hyperacute ischemic stroke. Stroke 2011;42:1307-1313.

26. Sargento-Freitas J, Pagola J, Rubiera M, Flores A, Silva F, Rodriguez-Luna $\mathrm{D}$, et al. Preferential effect of premorbid statins on atherothrombotic strokes through collateral circulation enhancement. Eur Neurol 2012;68:171-176.

27. Malik N, Hou Q, Vagal A, Patrie J, Xin W, Michel P, et al. Demographic and clinical predictors of leptomeningeal collaterals in stroke patients. J Stroke Cerebrovasc Dis 2014;23:2018-2022.

28. Lee MJ, Bang OY, Kim SJ, Kim GM, Chung CS, Lee KH, et al. Role of statin in atrial fibrillation-related stroke: an angiographic study for collateral flow. Cerebrovasc Dis 2014;37:77-84.

29. Pourati I, Kimmelstiel C, Rand W, Karas RH. Statin use is associated with enhanced collateralization of severely diseased coronary arteries. Am Heart J 2003;146:876-881.

30. Jonsson N, Asplund K. Does pretreatment with statins improve clinical outcome after stroke? A pilot case-referent study. Stroke 2001;32:1112-1115.

31. Marti-Fàbregas J, Gomis M, Arboix A, Aleu A, Pagonabarraga J, Belvis R, et al. Favorable outcome of ischemic stroke in patients pretreated with statins. Stroke 2004;35:1117-1121.

32. Greisenegger S, Mullner M, Tentschert S, Lang W, Lalouschek W. Effect of pretreatment with statins on the severity of acute ischemic cerebrovascular events. J Neurol Sci 2004;221:5-10.
33. Yoon SS, Dambrosia J, Chalela J, Ezzeddine M, Warach S, Haymore J, et al. Rising statin use and effect on ischemic stroke outcome. BMC Med 2004;2:4.

34. Elkind MS, Flint AC, Sciacca RR, Sacco RL. Lipid-lowering agent use at ischemic stroke onset is associated with decreased mortality. Neurology 2005;65:253-258.

35. Moonis M, Kane K, Schwiderski U, Sandage BW, Fisher M. HMG-CoA reductase inhibitors improve acute ischemic stroke outcome. Stroke 2005;36:1298-1300.

36. Aslanyan S, Weir CJ, McInnes GT, Reid JL, Walters MR, Lees KR. Statin administration prior to ischaemic stroke onset and survival: exploratory evidence from matched treatment-control study. Eur J Neurol 2005; 12:493-498.

37. Bushnell CD, Griffin J, Newby LK, Goldstein LB, Mahaffey KW, Graffagnino CA, et al. Statin use and sex-specific stroke outcomes in patients with vascular disease. Stroke 2006;37: 1427-1431.

38. Chitravas N, Dewey HM, Nicol MB, Harding DL, Pearce DC, Thrift AG. Is prestroke use of angiotensin-converting enzyme inhibitors associated with better outcome? Neurology 2007;68: 1687-1693.

39. Reeves MJ, Gargano JW, Luo Z, Mullard AJ, Jacobs BS, Majid A; Paul Coverdell National Acute Stroke Registry Michigan Prototype Investigators. Effect of pretreatment with statins on ischemic stroke outcomes. Stroke 2008;39:1779-1785.

40. Goldstein LB, Amarenco P, Zivin J, Messig M, Altafullah I, Callahan A, et al. Statin treatment and stroke outcome in the Stroke Prevention by Aggressive Reduction in Cholesterol Levels (SPARCL) trial. Stroke 2009;40:3526-3531.

41. Yu AY, Keezer MR, Zhu B, Wolfson C, Côté R. Pre-stroke use of antihypertensives, antiplatelets, or statins and early ischemic stroke outcomes. Cerebrovasc Dis 2009;27:398-402.

42. Martínez-Sánchez P, Rivera-Ordóñez C, Fuentes B, OrtegaCasarrubios MA, Idrovo L, Díez-Tejedor E. The beneficial effect of statins treatment by stroke subtype. Eur J Neurol 2009; 16:127-133.

43. Cuadrado-Godia E, Jiménez-Conde J, Ois A, RodríguezCampello A, García-Ramallo E, Roquer J. Sex differences in the prognostic value of the lipid profile after the first ischemic stroke. J Neurol 2009;256:989-995.

44. Stead LG, Vaidyanathan L, Kumar G, Bellolio MF, Brown RD $\mathrm{Jr}$, Suravaram S, et al. Statins in ischemic stroke: just low-density lipoprotein lowering or more? J Stroke Cerebrovasc Dis 2009; 18:124-127.

45. Arboix A, García-Eroles L, Oliveres M, Targa C, Balcells M, Massons J. Pretreatment with statins improves early outcome in patients with first-ever ischaemic stroke: a pleiotropic effect of statins or a beneficial effect of hypercholesterolemia? BMC 
Neurol 2010;10:47.

46. Sacco S, Toni D, Bignamini AA, Zaninelli A, Gensini GF, Carolei A; SIRIO Study Group. Effect of prior medical treatments on ischemic stroke severity and outcome. Funct Neurol 2011; 26:133-139.

47. Ní Chróinín D, Callaly EL, Duggan J, Merwick Á, Hannon N, Sheehan Ó, et al. Association between acute statin therapy, survival, and improved functional outcome after ischemic stroke: the North Dublin Population Stroke Study. Stroke 2011;42: 1021-1029.

48. Tsai NW, Lin TK, Chang WN, Jan CR, Huang CR, Chen SD, et al. Statin pre-treatment is associated with lower platelet activity and favorable outcome in patients with acute non-cardioembolic ischemic stroke. Crit Care 2011;15:R163.

49. Biffi A, Devan WJ, Anderson CD, Cortellini L, Furie KL, Rosand J, et al. Statin treatment and functional outcome after ischemic stroke: case-control and meta-analysis. Stroke 2011;42:1314-1319.

50. Hassan Y, Al-Jabi SW, Aziz NA, Looi I, Zyoud SH. Statin use prior to ischemic stroke onset is associated with decreased inhospital mortality. Fundam Clin Pharmacol 2011;25:388-394.

51. Flint AC, Kamel H, Navi BB, Rao VA, Faigeles BS, Conell C, et al. Inpatient statin use predicts improved ischemic stroke discharge disposition. Neurology 2012;78:1678-1683.

52. Flint AC, Kamel H, Navi BB, Rao VA, Faigeles BS, Conell C, et al. Statin use during ischemic stroke hospitalization is strongly associated with improved poststroke survival. Stroke 2012;43: 147-154.

53. Hjalmarsson C, Bokemark L, Manhem K, Mehlig K, Andersson $B$. The effect of statins on acute and long-term outcome after ischemic stroke in the elderly. Am J Geriatr Pharmacother 2012;10:313-322.

54. Aboa-Eboulé C, Binquet C, Jacquin A, Hervieu M, BonithonKopp C, Durier J, et al. Effect of previous statin therapy on severity and outcome in ischemic stroke patients: a populationbased study. J Neurol 2013;260:30-37.

55. Phipps MS, Zeevi N, Staff I, Fortunato G, Kuchel GA, McCullough LD. Stroke severity and outcomes for octogenarians receiving statins. Arch Gerontol Geriatr 2013;57:377-382.

56. Martínez-Sánchez P, Fuentes B, Martínez-Martínez M, RuizAres G, Fernández-Travieso J, Sanz-Cuesta BE, et al. Treatment with statins and ischemic stroke severity: does the dose matter? Neurology 2013;80:1800-1805.

57. Moonis M, Kumar R, Henninger N, Kane K, Fisher M. Pre and post-stroke use of statins improves stroke outcome. Indian J Community Med 2014;39:214-217.

58. Cordenier A, De Smedt A, Brouns R, Uyttenboogaart M, De Raedt S, Luijckx GJ, et al. Pre-stroke use of statins on stroke outcome: a meta-analysis of observational studies. Acta Neurol
Belg 2011;111:261-267.

59. Ní Chróinín D, Asplund K, Åsberg S, Callaly E, Cuadrado-Godia E, Díez-Tejedor E, et al. Statin therapy and outcome after ischemic stroke: systematic review and meta-analysis of observational studies and randomized trials. Stroke 2013;44:448-456.

60. Tsai NW, Lee LH, Huang CR, Chang WN, Chen SD, Wang $\mathrm{HC}$, et al. The association of statin therapy and high-sensitivity C-reactive protein level for predicting clinical outcome in acute non-cardioembolic ischemic stroke. Clin Chim Acta 2012;413: 1861-1865.

61. Yeh PS, Lin HJ, Chen PS, Lin SH, Wang WM, Yang CM, et al. Effect of statin treatment on three-month outcomes in patients with stroke-associated infection: a prospective cohort study. Eur J Neurol 2012;19:689-695.

62. Song B, Wang Y, Zhao X, Liu L, Wang C, Wang A, et al. Association between statin use and short-term outcome based on severity of ischemic stroke: a cohort study. PLoS One 2014;9: 84389.

63. Al-Khaled M, Matthis C, Eggers J. Statin treatment in patients with acute ischemic stroke. Int J Stroke 2014;9:597-601.

64. Blanco M, Nombela F, Castellanos M, Rodriguez-Yáñez M, García-Gil M, Leira R, et al. Statin treatment withdrawal in ischemic stroke: a controlled randomized study. Neurology 2007;69:904-910.

65. Alvarez-Sabín J, Huertas R, Quintana M, Rubiera M, Delgado P, Ribó M, et al. Prior statin use may be associated with improved stroke outcome after tissue plasminogen activator. Stroke 2007;38:1076-1078.

66. Bang OY, Saver JL, Liebeskind DS, Starkman S, Villablanca P, Salamon N, et al. Cholesterol level and symptomatic hemorrhagic transformation after ischemic stroke thrombolysis. Neurology 2007;68:737-742.

67. Uyttenboogaart M, Koch MW, Koopman K, Vroomen PC, Luijckx GJ, De Keyser J. Lipid profile, statin use, and outcome after intravenous thrombolysis for acute ischaemic stroke. $J$ Neurol 2008;255:875-880.

68. Meier N, Nedeltchev K, Brekenfeld C, Galimanis A, Fischer U, Findling $\mathrm{O}$, et al. Prior statin use, intracranial hemorrhage, and outcome after intra-arterial thrombolysis for acute ischemic stroke. Stroke 2009;40:1729-1737.

69. Restrepo L, Bang OY, Ovbiagele B, Ali L, Kim D, Liebeskind DS, et al. Impact of hyperlipidemia and statins on ischemic stroke outcomes after intra-arterial fibrinolysis and percutaneous mechanical embolectomy. Cerebrovasc Dis 2009;28:384-390.

70. Miedema I, Uyttenboogaart M, Koopman K, De Keyser J, Luijckx GJ. Statin use and functional outcome after tissue plasminogen activator treatment in acute ischaemic stroke. Cerebrovasc Dis 2010;29:263-267. 
71. Engelter ST, Soinne L, Ringleb P, Sarikaya H, Bordet R, Berrouschot J, et al. IV thrombolysis and statins. Neurology 2011; 77:888-895.

72. Cappellari M, Deluca C, Tinazzi M, Tomelleri G, Carletti M, Fiaschi $\mathrm{A}$, et al. Does statin in the acute phase of ischemic stroke improve outcome after intravenous thrombolysis? A retrospective study. J Neurol Sci 2011;308:128-134.

73. Meseguer E, Mazighi M, Lapergue B, Labreuche J, Sirimarco G, Gonzalez-Valcarcel J, et al. Outcomes after thrombolysis in AIS according to prior statin use: a registry and review. Neurology 2012;79:1817-1823.

74. Rocco A, Sykora M, Ringleb P, Diedler J. Impact of statin use and lipid profile on symptomatic intracerebral haemorrhage, outcome and mortality after intravenous thrombolysis in acute stroke. Cerebrovasc Dis 2012;33:362-368.

75. Martinez-Ramirez S, Delgado-Mederos R, Marin R, SuárezCalvet M, Sáinz MP, Alejaldre A, et al. Statin pretreatment may increase the risk of symptomatic intracranial haemorrhage in thrombolysis for ischemic stroke: results from a case-control study and a meta-analysis. J Neurol 2012;259:111-118.

76. Cappellari M, Bovi P, Moretto G, Zini A, Nencini P, Sessa M, et al. The THRombolysis and STatins (THRaST) study. Neurology 2013;80:655-661.

77. Zhao HD, Zhang YD. The effects of previous statin treatment on plasma matrix metalloproteinase-9 level in chinese stroke patients undergoing thrombolysis. J Stroke Cerebrovasc Dis 2014; 23:2788-2793.

78. Scheitz JF, Seiffge DJ, Tütüncü S, Gensicke H, Audebert HJ, Bonati LH, et al. Dose-related effects of statins on symptomatic intracerebral hemorrhage and outcome after thrombolysis for ischemic stroke. Stroke 2014;45:509-514.

79. Scheitz JF, Endres M, Heuschmann PU, Audebert HJ, Nolte $\mathrm{CH}$. Reduced risk of poststroke pneumonia in thrombolyzed stroke patients with continued statin treatment. Int J Stroke 2015; 10:61-66.

80. Rodríguez de Antonio LA, Martínez-Sánchez P, MartínezMartínez MM, Cazorla-García R, Sanz-Gallego I, Fuentes B, et al. Previous statins treatment and risk of post-stroke infections. Neurologia 2011;26:150-156.

81. Rodríguez-Sanz A, Fuentes B, Martínez-Sánchez P, Prefasi D, Martínez-Martínez M, Correas E, et al. High-density lipoprotein: a novel marker for risk of in-hospital infection in acute ischemic stroke patients? Cerebrovasc Dis 2013;35:291-297.

82. Becker K, Tanzi P, Kalil A, Shibata D, Cain K. Early statin use is associated with increased risk of infection after stroke. J Stroke
Cerebrovasc Dis 2013;22:66-71.

83. Kennedy J, Hill MD, Ryckborst KJ, Eliasziw M, Demchuk AM, Buchan AM; FASTER Investigators. Fast assessment of stroke and transient ischaemic attack to prevent early recurrence (FASTER): a randomised controlled pilot trial. Lancet Neurol 2007;6:961-969.

84. Montaner J, Chacón P, Krupinski J, Rubio F, Millán M, Molina CA, et al. Simvastatin in the acute phase of ischemic stroke: a safety and efficacy pilot trial. Eur J Neurol 2008;15:82-90.

85. Muscari A, Puddu GM, Santoro N, Serafini C, Cenni A, Rossi $\mathrm{V}$, et al. The atorvastatin during ischemic stroke study: a pilot randomized controlled trial. Clin Neuropharmacol 2011;34: 141-147.

86. Beer C, Blacker D, Bynevelt M, Hankey GJ, Puddey IB. A randomized placebo controlled trial of early treatment of acute ischemic stroke with atorvastatin and irbesartan. Int J Stroke 2012;7:104-111.

87. Zare M, Saadatnia M, Mousavi SA, Keyhanian K, Davoudi V, Khanmohammadi $\mathrm{E}$. The effect of statin therapy in stroke outcome: a double blind clinical trial. Int J Prev Med 2012;3:68-72.

88. Squizzato A, Romualdi E, Dentali F, Ageno W. Statins for acute ischemic stroke. Cochrane Database Syst Rev 2011; (8): CD007551.

89. Elkind MS, Sacco RL, Macarthur RB, Peerschke E, Neils G, Andrews $\mathrm{H}$, et al. High-dose lovastatin for acute ischemic stroke: results of the phase I dose escalation neuroprotection with statin therapy for acute recovery trial (NeuSTART). Cerebrovasc Dis 2009;28:266-275.

90. Jauch EC, Saver JL, Adams HP Jr, Bruno A, Connors JJ, Demaerschalk BM, et al. Guidelines for the early management of patients with acute ischemic stroke: a guideline for healthcare professionals from the American Heart Association/American Stroke Association. Stroke 2013;44:870-947.

91. Choi JC, Lee JS, Park TH, Cho YJ, Park JM, Kang K, et al. Effect of pre-stroke statin use on stroke severity and early functional recovery: a retrospective cohort study. BMC Neurol 2015;15: 120.

92. Bavry AA, Mood GR, Kumbhani DJ, Borek PP, Askari AT, Bhatt DL. Long-term benefit of statin therapy initiated during hospitalization for an acute coronary syndrome: a systematic review of randomized trials. Am J Cardiovasc Drugs 2007;7: 135-141.

93. Afilalo J, Majdan AA, Eisenberg MJ. Intensive statin therapy in acute coronary syndromes and stable coronary heart disease: a comparative meta-analysis of randomised controlled trials. Heart 2007;93:914-921. 


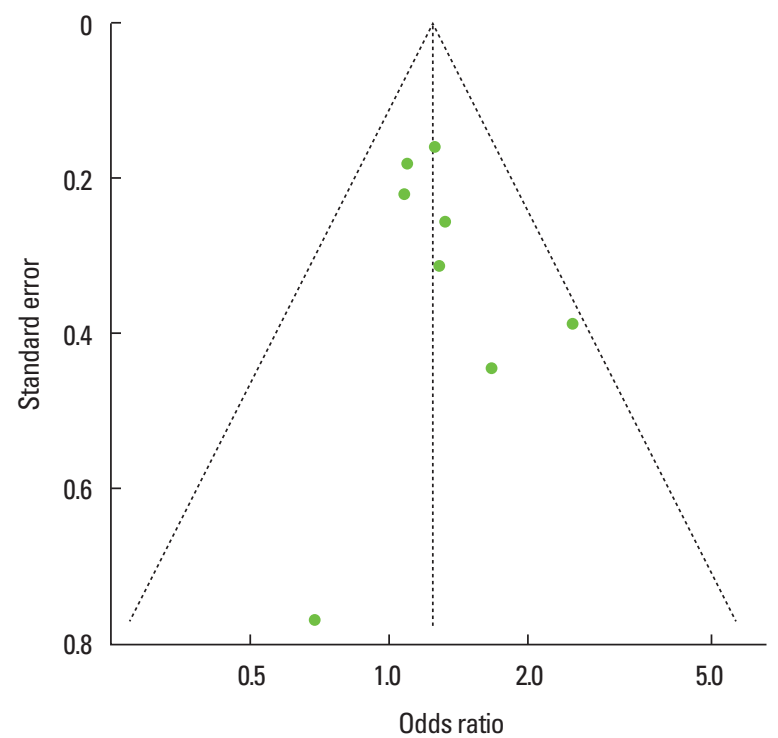

Supplemental Figure 1. Pre-stroke statin effect on initial stroke severity. Begg's test for publication bias: $P=0.322$.

Odds Ratio

Study or Subaroup

Yu

Sacco

Hjalmarsson

Martínez-Sánchez Low to Mod

Phipps

Martínez-Sánchez High

\section{loa[Odds Ratio}

$\begin{array}{lll}0.2546 & 0.3125\end{array}$

0.09530 .1815

$0.2776 \quad 0.2555$

0.22230 .1588

$\begin{array}{lll}0.077 & 0.2193\end{array}$

$\begin{array}{lll}0.9167 & 0.3863\end{array}$
Weight IV.Random. 95\% Cl Year

$\begin{array}{lll}8.3 \% & 1.29[0.70,2.38] 2009\end{array}$

$24.7 \% \quad 1.10[0.77,1.57] 2011$

$12.4 \% \quad 1.32[0.80,2.18] 2012$

$32.2 \% \quad 1.25[0.91,1.70] 2013$

$16.9 \% \quad 1.08[0.70,1.66] 2013$

$5.4 \% \quad 2.50[1.17,5.33] 2013$

Total $(95 \% \mathrm{Cl})$

$100.0 \%$

Heterogeneity: $\mathrm{Tau}^{2}=0.00 ; \mathrm{Ch}^{2}=4.21, \mathrm{df}=5(\mathrm{P}=0.52) ; \mathrm{I}^{2}=0 \%$

Test for overall effect: $Z=2.37(P=0.02)$

\section{$1.24[1.04,1.48]$}

Supplemental Figure 2. Pre-stroke statin effect on initial stroke severity. Pooling 5 studies providing adjusted ORs.

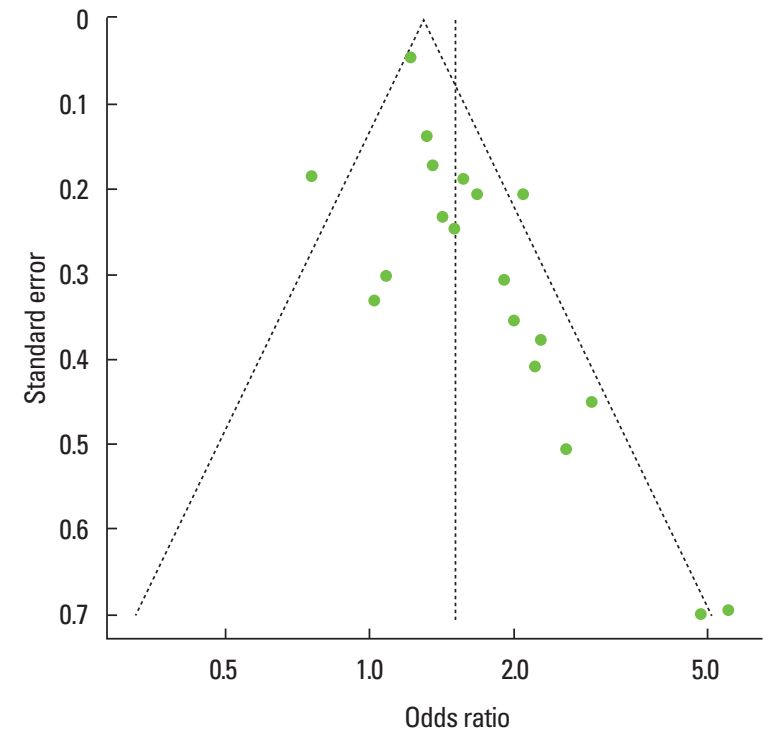

Supplemental Figure 3. Pre-stroke statin effect on functional outcome. Begg's test for publication bias: $P=0.001$.

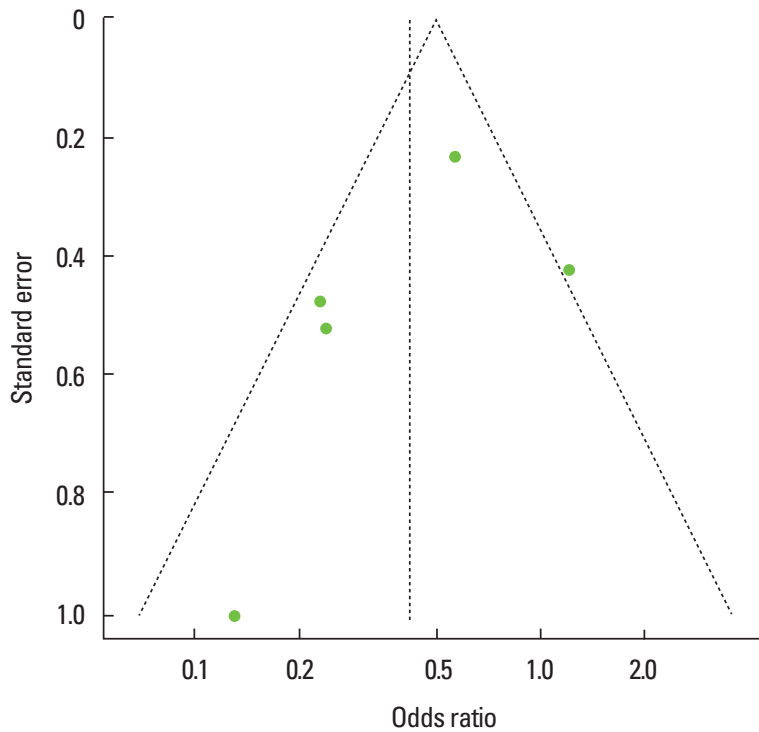

Supplemental Figure 4. Pre-stroke statin effect on short-term mortality. Begg's test for publication bias: $P=0.624$. 
Odds Ratio

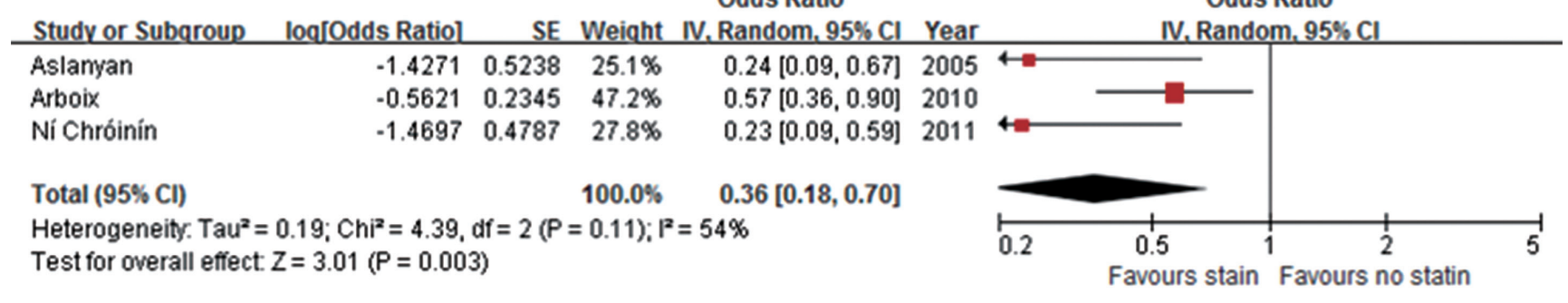

Supplemental Figure 5. Pre-stroke statin effect on mortality. Pooling 3 studies providing adjusted ORs.

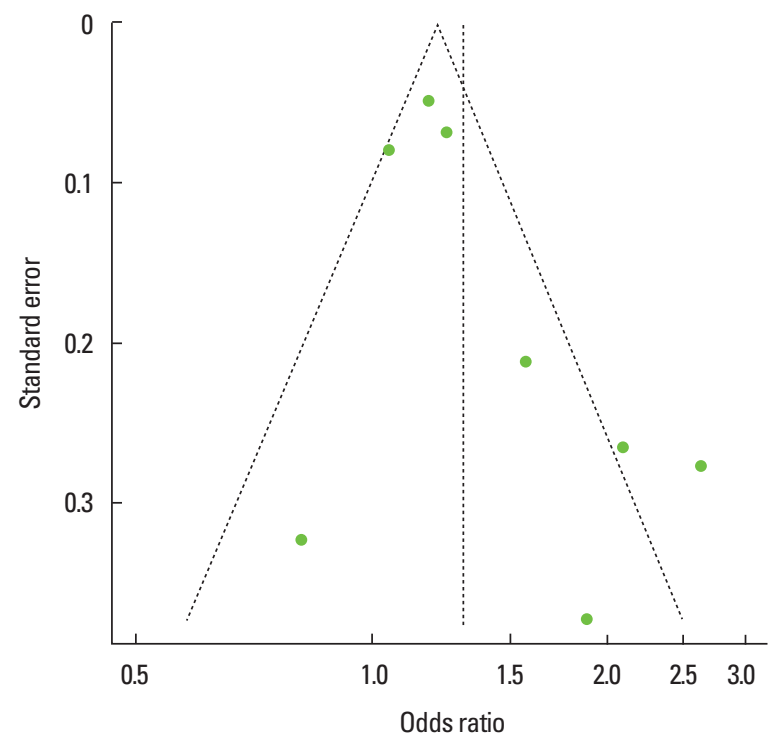

Supplemental Figure 6. In-hospital statin effect on functional outcome. Begg's test for publication bias: $P=0.322$.

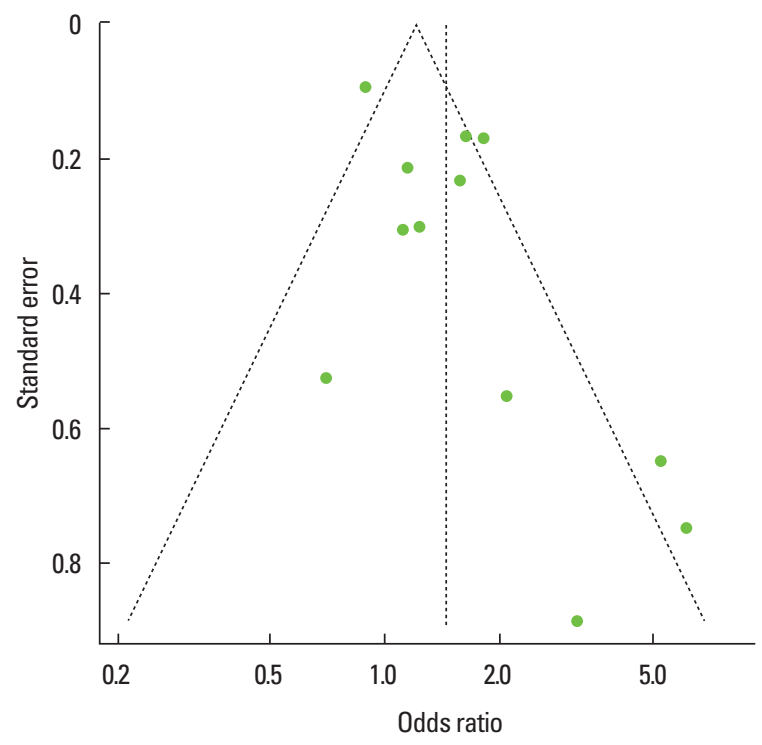

Supplemental Figure 7. Statin effect on functional outcome in patients treated with thrombolysis. Begg's test for publication bias: $P=0.493$.

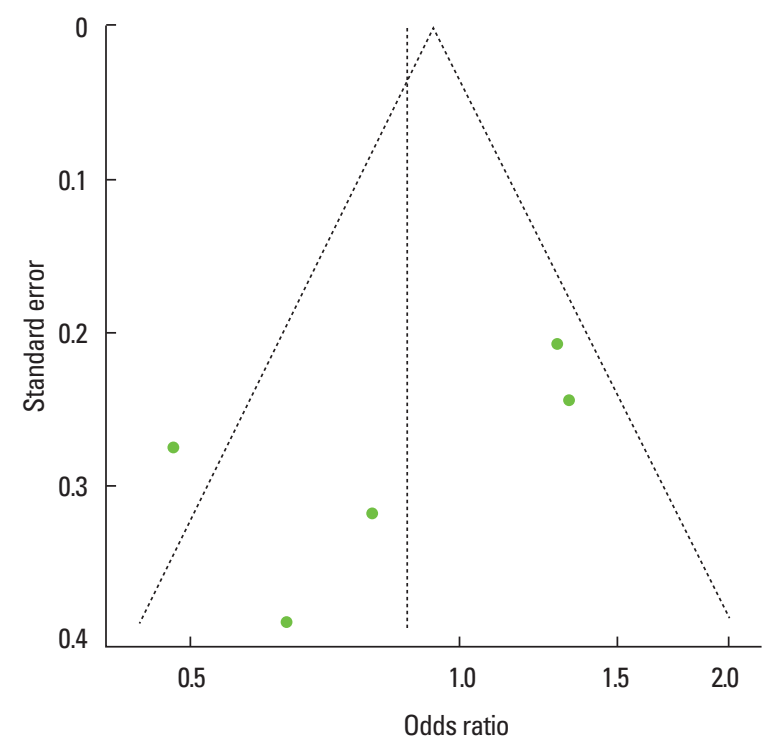

Supplemental Figure 8. Statin effect on mortality in patients treated with thrombolysis. Begg's test for publication bias: $P=0.142$. 
Odds Ratio

\begin{tabular}{|c|c|c|c|c|c|}
\hline Study or Subgroup & log[Odds Ratio] & SE & Weight & V. Random, $95 \% \mathrm{Cl}$ & Yea \\
\hline Meseguer & -0.2231 & 0.3167 & $24.2 \%$ & $0.80[0.43,1.49]$ & 2012 \\
\hline Rocco & 0.2776 & 0.2429 & $29.0 \%$ & $1.32[0.82,2.12]$ & 12 \\
\hline Cappellari 2013 & -0.734 & 0.275 & $26.8 \%$ & $0.48[0.28,0.82]$ & 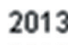 \\
\hline Scheitz 2015 & -0.4463 & 0.3883 & $20.1 \%$ & $0.64[0.30,1.37]$ & \\
\hline Total $(95 \% \mathrm{Cl})$ & & & $100.0 \%$ & $0.77[0.48,1.25]$ & \\
\hline
\end{tabular}

Odds Ratio IV, Random, $95 \% \mathrm{Cl}$

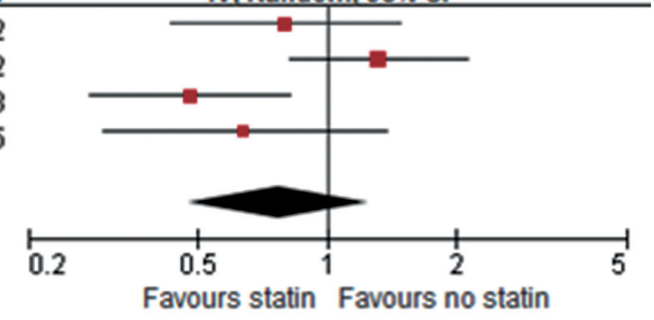

Supplemental Figure 9. Statin effect on mortality in patients with thrombolysis. Pooling 4 studies providing adjusted ORs.

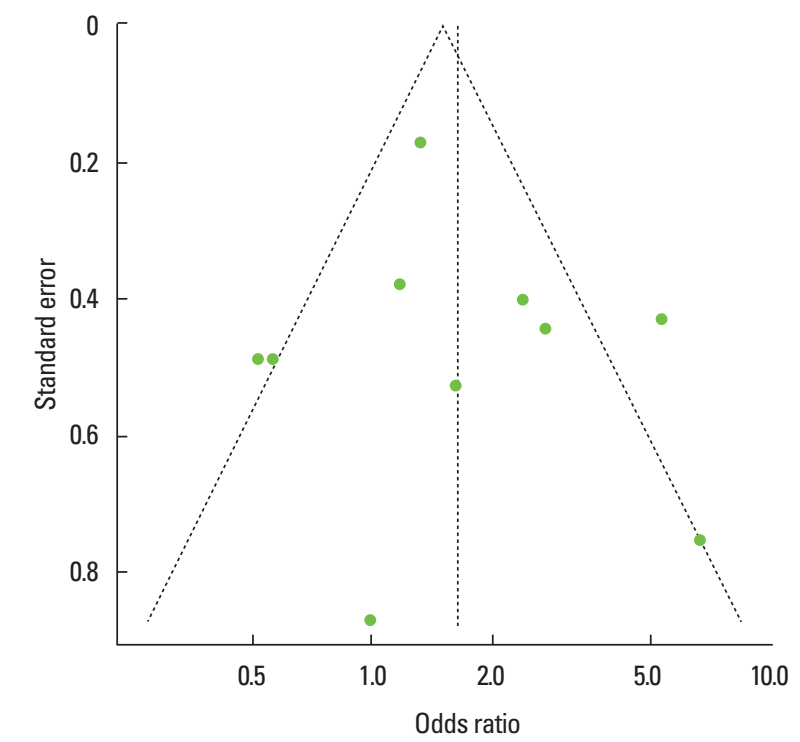

Supplemental Figure 10. Statin effect on symptomatic hemorrhagic transformation in patients treated with thrombolysis. Begg's test for publication bias: $P=0.655$.

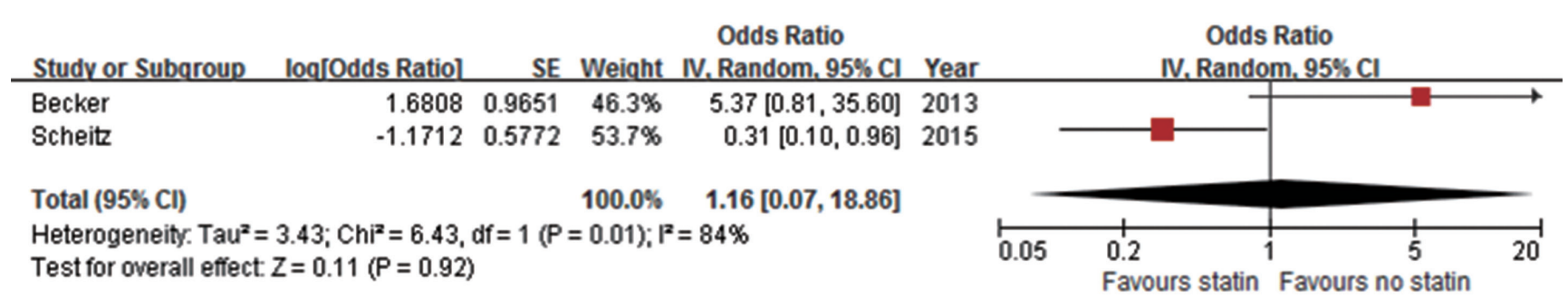

Supplemental Figure 11. Statin effect on post-stroke infection. Pooling 2 studies providing adjusted ORs. 